\title{
Parental provisioning drives brain size in birds
}

3 Griesser, Michael 1-4

Drobniak, Szymon M. 5-6

Graber, Sereina M. 4

6 van Schaik, Carel P. 4,7

1) Department of Biology, University of Konstanz, Konstanz, Germany

9 2) Center for the Advanced Study of Collective Behavior, University of Konstanz, Konstanz, Germany.

3) Department of Collective Behavior, Max Planck Institute of Animal Behavior, Konstanz,

12 Germany

4) Department of Anthropology, University of Zurich, Zurich, Switzerland

5) Evolution \& Ecology Research Centre, School of Biological, Environmental \& Earth

15 Sciences, University of New South Wales, Sydney, Australia

6) Institute of Environmental Sciences; Jagiellonian University, Krakow, Poland

7) Centre for Interdisciplinary Study of Language Evolution, University of Zurich, Zürich,

18 Switzerland

\section{Contact information}

21 Michael Griesser: michael.griesser@uni-konstanz.de 


\section{Abstract}

Larger brains should be adaptive because they support numerous eco- and socio-cognitive benefits, but these benefits explain only a modest part of the interspecific variation in brain size. Notably underexplored are the high energetic costs of developing brains, and thus the possible role of parental provisioning in the evolution of adult brain size. We explore this idea in birds, which show considerable variation in both socio-ecological traits and the energy transfer from parents to offspring. Comparative analyses of 1,176 bird species show that the combination of adult body mass, mode of development at hatching, relative egg mass, and the time spent provisioning the young in combination strongly predict relative brain size across species. Adding adult eco- and socio-cognitive predictors only marginally adds explanatory value. We therefore conclude that parental provisioning enabled bird species to evolve into skill-intensive niches, reducing interspecific competition and consequently promoting survival prospects and population stability. Critically, parental provisioning also explains why precocial bird species have smaller brains than altricial ones. Finally, these results suggest that the cognitive adaptations that provide the behavioral flexibility to improve reproductive success and survival are intrinsically linked to successful parental provisioning. Our findings also suggest that the traditionally assessed cognitive abilities may not predict relative brain size.

\section{Significance statement}

Species vary substantially in their brain size, and the idea that larger-brained species are those with a complex social life or enhanced technological skills has generated much interest. Here we explore another explanation. Because the cognitive benefits provided by brains materialize after a long delay, and constructing them independently involves a major bootstrapping problem for the young, parental inputs may be critical for a species' brain size. Comparative analyses of a large sample of bird species show that parental provisioning strongly predicts relative brain size across species, swamping the effects of previously considered social or technological cognitive abilities. Thus, cognitive adaptations in birds that enable successful parental provisioning also provide the behavioral flexibility to improve survival and reproductive success. 


\section{Introduction}

Brain size varies extensively within and across lineages, and has increased considerably over

57 evolutionary time (1). This intriguing variability has raised questions about the adaptive benefits of increased relative brain size (i.e., relative to adult body mass). An obvious benefit is improved cognitive abilities (2-4), and numerous comparative studies explored this idea.

60 In mammals, work has prominently focused on the social brain hypothesis, which emphasizes the social benefits of relatively larger brains, but eco-cognitive benefits have also been explored (5-7). In birds, work focused on both social drivers, especially pair bond maintenance $(5,7,8)$, and ecological ones, especially environmental variability (9-12). Whereas comparative studies have difficulty assessing whether larger brains improve reproductive success, they can more easily show whether they improve survival. Indeed, comparative studies support a positive association between relative brain size and longevity in diverse lineages (13-15).

Other research independently focused on the high energy costs of brain tissue $(16,17)$. This aspect is pivotal for the expensive tissue hypothesis, which focuses on the trade-off between brain size and other energetically expensive tissues, such as guts (18). Subsequent work highlighted a general link between relative brain size and the energy available to sustaining the brain (19). These costs imply that natural selection cannot always respond to opportunities to evolve specific cognitive adaptations via an increase in brain size, even if this would in principle lead to higher fitness. Indeed, recent comparative work has found that species living in fluctuating environments that cause inevitable reductions of energy intake show reduced relative brain size $(20,21)$. These trade-offs also have a developmental aspect: the maternal energy hypothesis (22) argues that the ability of mammalian mothers to transfer energy to their offspring constrains brain size (23). Various studies reported a link between maternal allocation and relative brain size in mammals $(23,24)$, birds (8), cichlid fish (25), and sharks and rays (26). However, they failed to provide an adaptive explanation for this association or did not evaluate alternative or complementary hypotheses.

Here we propose that paying systematic attention to the developmental costs of brains should improve our understanding of brain size evolution via its correlated evolution with 
parental provisioning. Offspring face a seemingly insurmountable bootstrapping problem posed by growing and differentiating large brains. How can offspring develop large brains when they would need them to provide the energy necessary for this process? This catch-22 leads to the prediction that adult brain size across species depends on the parents' capacity to provision their young. Thus, we examine the effect of parental provisioning on relative brain size in birds, while simultaneously assessing hypotheses proposing eco- or sociocognitive benefits. This lineage is well suited for an integrated test of these different hypotheses: birds show appreciable variation in many relevant traits, and the energy transfer from parents to offspring can readily be assessed via egg volumes and the time offspring are provisioned. Moreover, birds have a deeply rooted split in the developmental state of the hatchlings, ranging from precocial (no or little provisioning of the young) to altricial (extended provisioning), henceforth referred to as developmental mode (27).

Previous work noted that precocial species have smaller adult brain size than altricial ones $(28,29)$, but the evolutionary causes of this pattern remain unclear. Birds also vary in the number of providers (30). These differences allow us to distinguish the effects of investment in eggs from those of provisioning of young. Moreover, birds show major variation in ecology (aspects of their ecological niche, the climate in their geographic range) (31) and in sociality (32).

This high variability in all relevant variables in birds allowed us to simultaneously test all these effects on adult brain size. We assembled information on adult brain size, adult body mass, predictors assessing parental provisioning (egg mass, clutch size, duration of food provisioning, number of providers), ecology (fiber and energy content of food, complexity of food acquisition, foraging substrate, sedentariness, insularity, climate in the geographic range), and sociality (strength and stability of pair bonds, breeding alone or in colonies, group sizes outside the breeding season) for 1,176 bird species. For the comparative tests, we used phylogenetically controlled Bayesian mixed models (33) to assess the effects on 114 relative brain size across species of i) parental provisioning, ii) eco-social predictors, and iii) all predictors combined. Next, to understand how the different predictors may have affected each other's evolution, we used phylogenetic d-separation path analysis (34).

\section{Results}


Because body mass is tightly correlated with brain size, any model that incorporates body mass as an independent predictor of brain size will tend to mask the impact of the other, more informative predictors. We therefore report the results using relative brain size scaled by body mass as the response variable, but note that analyses including absolute brain size as a response variable produce qualitatively the same results (see S1a-c Table). Moreover, body mass scales many aspects of bird physiology and life-history in a non-linear manner. Thus, we include body mass and its interaction with key predictors in all models to capture these nonlinearities.

Phylogenetically controlled mixed models showed that larger relative brain sizes in birds

129 were positively associated with all components of parental provisioning (Fig 1, S2a-d Tables). Larger relative brains were found in species that are altricial, have larger relative egg mass, smaller clutches, and feed their young for a longer time. The effect of these predictors was modified by interactions among them, further highlighting the importance of parental provisioning (Fig 1). Accordingly, only precocial species showed a negative correlation between relative brain size and clutch size (Fig 2a), while only altricial species showed a positive correlation between relative brain size and the time offspring are fed (Fig $2 b)$. The remaining interaction effects reflected fundamental allometries or differences in body mass between precocial and altricial species (Fig 1). In sum, the total amount of energy invested into each individual young strongly affected adult brain size.

\section{Fig 1. Estimated coefficients and effect sizes of phylogenetically controlled mixed models}

141 of the parental provisioning model, the eco-social model, and the combined model on relative brain size in birds. Color-filled circles denote estimated effects, lines denote the 95\% lower and upper confidence limits generated in the R package MCMCgImm (33) based

144 on a consensus phylogeny. Symbols below the circles denote the proportion of random tree models that reach statistical significance $(p<0.05)$ for each predictor based on model averaging of 200 models, using a set of random trees from http://birdtree.org (35). The

147 corresponding full models are shown in S2a-c Table. 


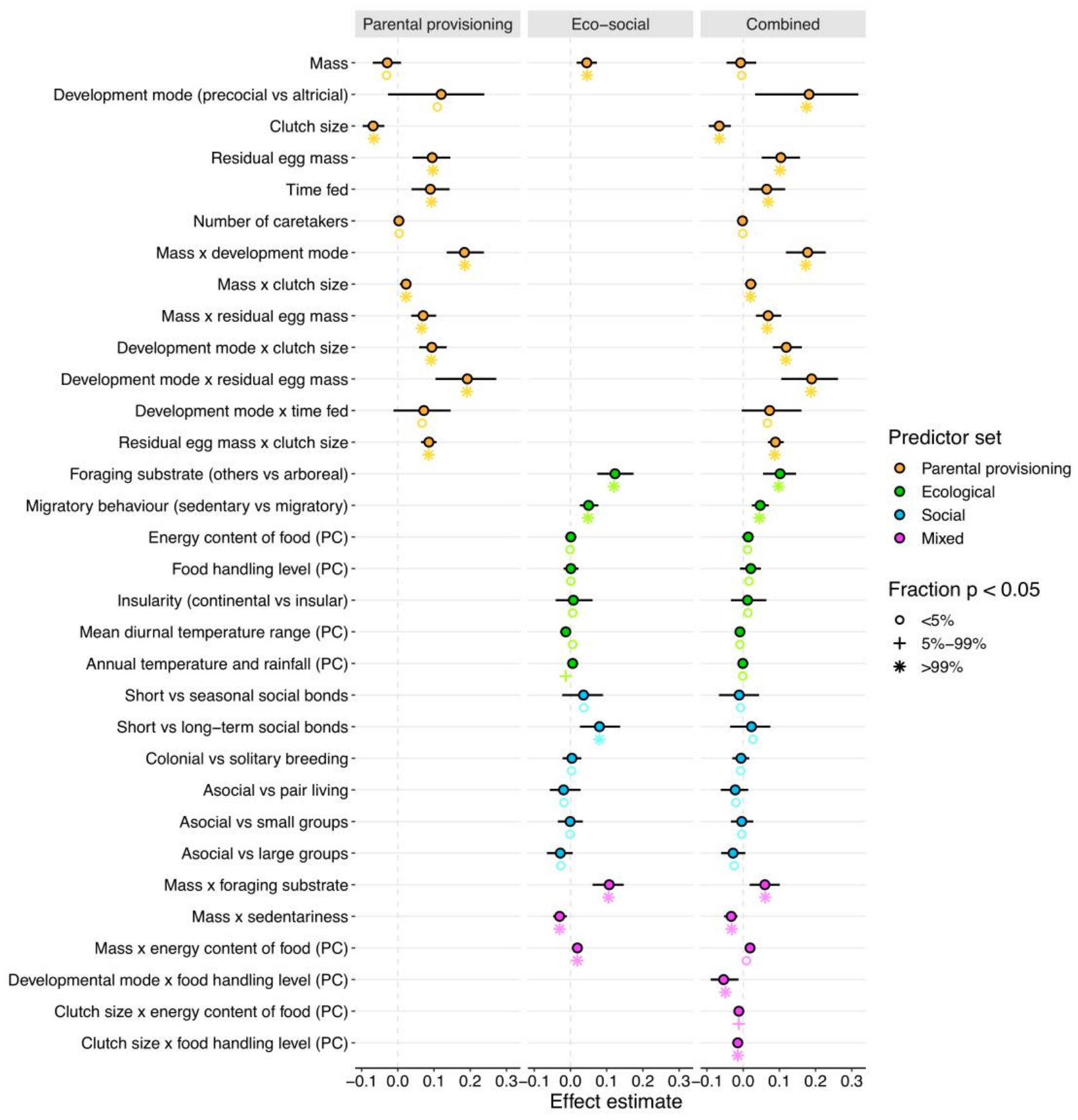

150 When only examining the effect of eco-social predictors on relative brain size, phylogenetically controlled mixed models primarily showed that sedentary species and those that forage arboreally, had larger relative brain size than those that are migratory or

153 use other foraging substrates (Fig 2c,d). In terms of interaction effects, we found that relative brain size increases with body mass only in arboreal foragers, and that higher energy content of food translated into larger relative brain size only in larger species (Fig 1).

156 Social factors had a much weaker impact on relative brain size: species with enduring pair 
bonds tended to have a larger relative brain size than species without pair bonds, whereas no correlations were found for the other social predictors (Fig 1).

Fig 2. The effect of parental provisioning $(a, b)$ and ecological parameters $(c, d)$ on relative brain size in birds ( $N=1,176$ species). a) Clutch size vs developmental mode (precocial vs

162 altricial). b) Time provisioned vs developmental mode (precocial vs altricial). c) Movement pattern: sedentary vs migratory. d) Foraging substrate: others vs arboreal. In $\mathbf{a}-\mathbf{b}$, solid lines designate linear trend estimates, grey shading designate standard error bands. In c-d, thick

165 lines designate medians, the grey boxes designate inter-quantile ranges (IQR, 0.25-0.75 quantile), whiskers designate \pm 1.5 IQR, circles designate outliers.
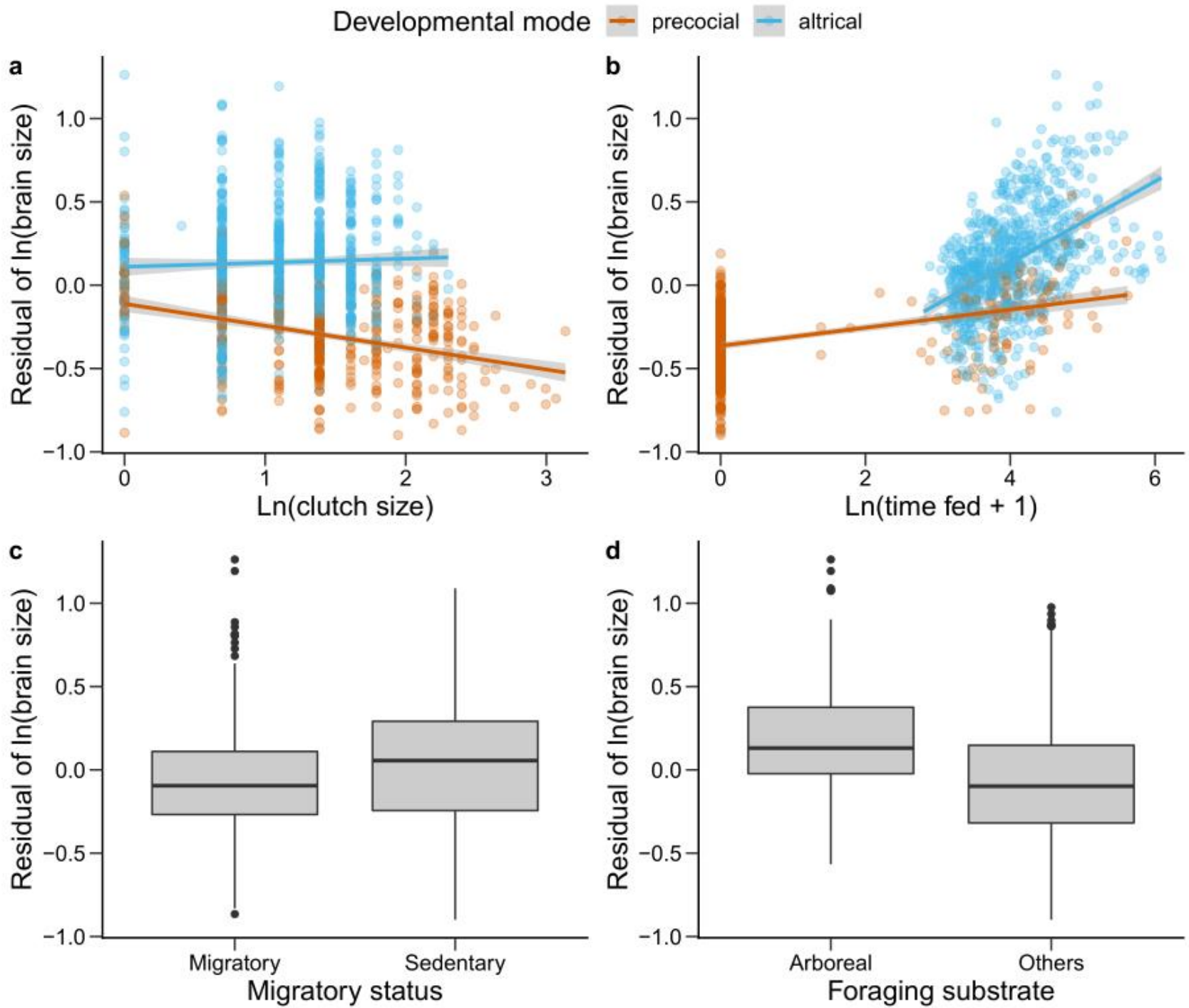
The eco-social model explained markedly less variance in relative brain sizes than the

171 parental provisioning model $\left(R^{2}=0.38\right.$ vs $\left.R^{2}=0.50\right)$. However, a combined model containing both parental provisioning and eco-social predictors performed best $\left(R^{2}=0.57\right)$. Although confirming the patterns of the separate models (Fig 1), it revealed that the posterior

174 estimates of effect sizes of parental provisioning were far larger than those of the eco-social factors. Among the latter, the ecological predictors that remain significant in the combined model were largely linked to the adult foraging niche and movement patterns, whereas

177 social predictors no longer played any role.

Additional models showed that data limitations are not responsible for the observed patterns. Models that excluded parameters with limited data availability (time fed, social grouping; S3 a-b Tables) confirmed a key role of parental provisioning for relative brain size. Similarly, using a more detailed categorization of the development mode spectrum instead of binary categorization recovered the same patterns (S3c Table), and so did a model that controlled for the possible confounding effect of longevity on parental provisioning parameters (S2d Table).

The effect of parental provisioning on relative brain size became obvious when superimposed on a phylogenetic tree (Fig 3). Starting at 3 o'clock and moving counter-

189 clockwise, early emerging, precocial lineages had relatively small brains, while interdispersed altricial lineages (seabirds, pigeons, hummingbirds, swifts) had slightly larger brains. With the origin of Inopinaves (core land birds) (36) some 65 million years ago,

192 systematic altriciality and extensive parental provisioning arose, resulting in several clusters of notably large-brained lineages, including owls, parrots, and corvids, while one lineage (nightjars) reverted to precociality and small brains. The most recently evolved and highly diverse other passerines were small-bodied and did not have brains of exceptionally large relative size, although they are still relatively larger than those of precocial lineages.

198 Fig 3. Phylogenetic distribution of relative brain size, developmental mode (precocial vs altricial), and time parent(s) feed their offspring ( $N=1,176$ bird species). Size of bars in outer circle represent body mass (In(grams)); size of bars in middle circle represents relative brain size $(\ln (\mathrm{mL}))$ while their color represents the time parents feed their offspring $(\operatorname{In}$ (days 
bioRxiv preprint doi: https://doi.org/10.1101/2021.12.19.470191; this version posted December 21, 2021. The copyright holder for this preprint (which was not certified by peer review) is the author/funder, who has granted bioRxiv a license to display the preprint in perpetuity. It is made available under aCC-BY-NC-ND 4.0 International license.

+ 1)); inner circle represents developmental mode (precocial, altricial). Phylogeny follows birdrtree.org (35), whereas taxonomy largely follows Prum et al. (36), explaining why some clades appear polyphyletic.

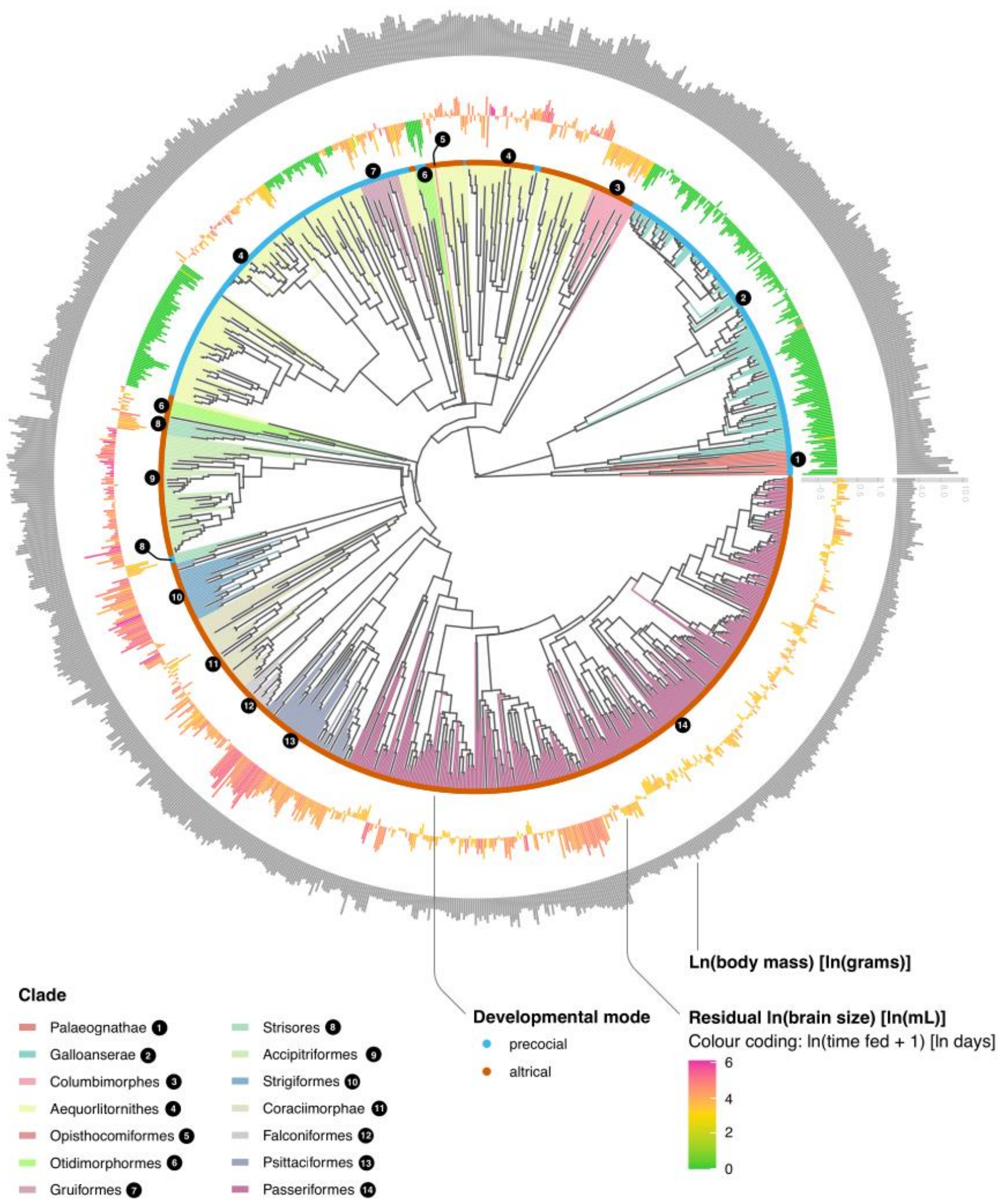


Because the predictors analyzed above may not only have affected relative brain size directly, but may also have selected for evolutionary changes in values of other predictors and thus affected brain size indirectly, we performed phylogenetic path analyses $(34,37)$ to gain better insights into the causal relationships between traits. We included wellestablished developmental and eco-social relationships in all models, but also added biologically plausible ones involving brain size that were varied across the different models.

The model assessing the relationships among the various parental provisioning predictors of relative brain size showed that adult body mass affects all other traits, including developmental mode (Fig 4a). Both a large adult body mass and altriciality had a negative effect on clutch size and residual egg mass. Altriciality had a strong positive effect on the time offspring are fed, and subsequently on brain size. These patterns reflect established

219 life-history trade-offs and their cascading effects on the total amount of energy transferred from parents to their offspring at the different developmental stages. The remaining effect of body mass on relative brain size depended on developmental mode, reflecting that larger altricial species had larger relative brain sizes than precocial species, relative to what would be predicted from body size alone (see Fig 1 ). This pattern therefore fully supports the pervasive effect of parental provisioning on a species' brain size.

Turning to the eco-social predictors, the path model assessing the evolutionary relationships among them showed that some of these predictors have strong evolutionary links among themselves, but rather weak selective effects on relative brain size (Fig $4 b$ ). A combined path analysis (S1 Fig) including both parental provisioning and eco-social predictors retained the relationships revealed by the separate and combined phylogenetically controlled mixed models. Parental provisioning continued to have a direct and strong effect on relative brain size, whereas that of the eco-social variables remains weak.

234 Fig 4. Phylogenetic associations among predictors and relative brain size, assessed by dseparation path analyses (34) ( $\mathbf{N = 1 , 1 7 6}$ bird species). Arrows thickness and numeric values show the strength of the association, arrow color shows its direction (positive: orange, negative: blue). a, Associations among parental provisioning predictors. b, Associations 
bioRxiv preprint doi: https://doi.org/10.1101/2021.12.19.470191; this version posted December 21, 2021. The copyright holder for this preprint (which was not certified by peer review) is the author/funder, who has granted bioRxiv a license to display the preprint in perpetuity. It is made available under aCC-BY-NC-ND 4.0 International license.

among eco-social predictors. The plot showing the model including both the parental provisioning and eco-social parameters is shown in S1 Fig.

a
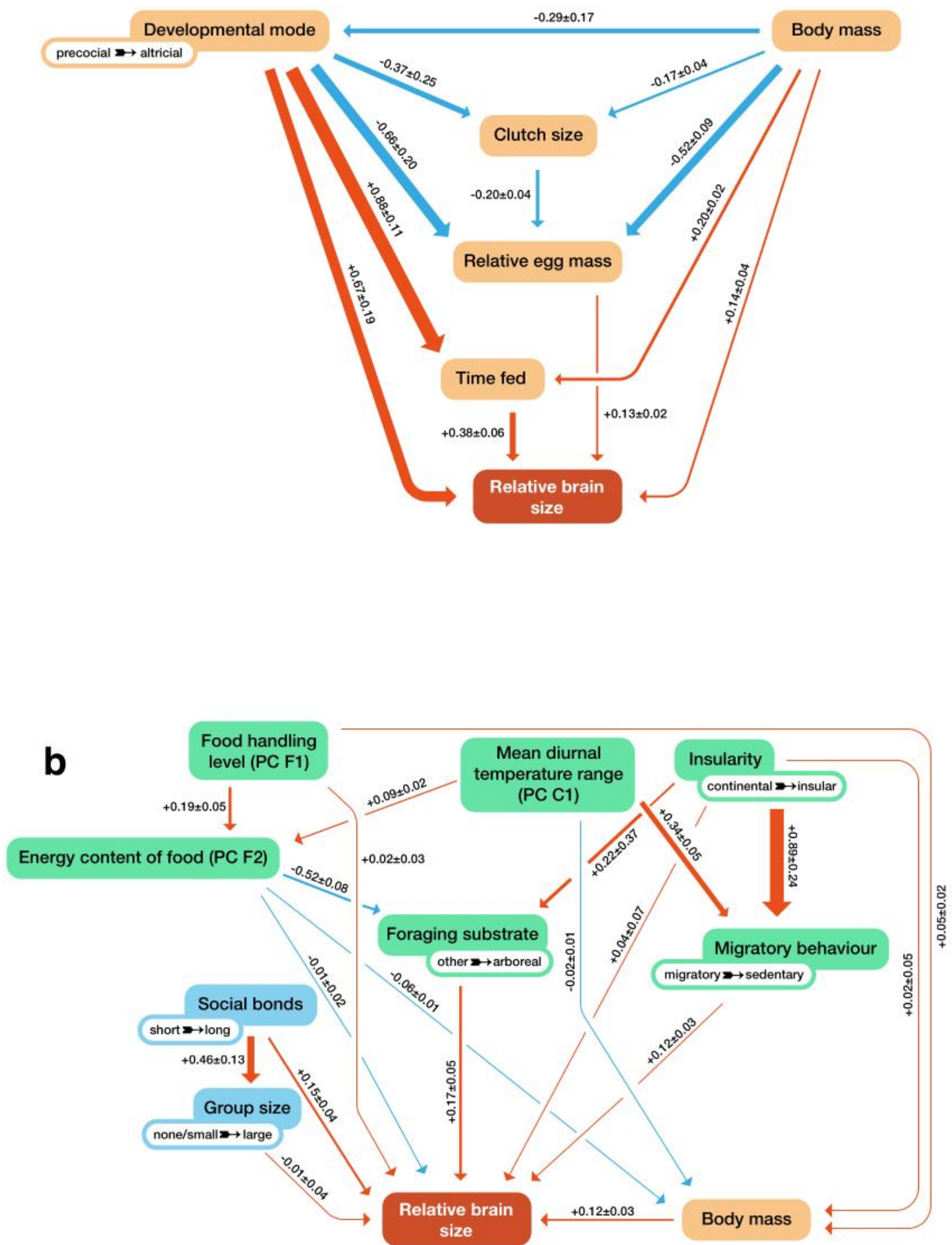
These findings have three major implications, which we now discuss in turn. First, parental provisioning is the main predictor of adult relative brain size in birds: in the combined model, adult eco- and socio-cognitive demands hardly play a role. Thus, large brains can only be sustained in species with extensive energy inputs during development. This association is supported by previous work in diverse lineages $(8,24-26)$. However, these

249 studies either did not provide an underlying mechanism or did not consider the relationship to reflect adaptation $(23,24)$. The parental provisioning hypothesis offers a novel theoretical underpinning to this pattern. Parental provisioning enables growing young to construct a large brain during a life stage when they themselves have not yet learned the skills needed to acquire the energy necessary to sustain such a growing and learning brain. Accordingly, parental provisioning removed this bottleneck for the evolution of larger brain size, and enabled bird species to evolve into skill-intensive niches, which reduce interspecific competition and thereby promoting survival prospects and population stability (see (12)). Its importance is also highlighted by the phylogenetic path analyses, which confirm that its components form a tightly coevolved set.

Second, the parental provisioning hypothesis can explain the well-established pattern that 261 altricial species have relatively larger brains than precocial $(28,29)$. Precocial young are only provisioned through egg mass, which is subject to obvious physical limitations. As a result, they experience serious constraints on relative brain size and therefore niche complexity.

264 The evolutionary transitions to altriciality allowed species to evolve into cognitively more demanding niches, which require more elaborate food-handling or anti-predator skills (29). This was made possible by parents donating the requisite large brain through extended 267 parental provisioning. However, these transitions were actually quite rare (29). Although the underlying reasons for this rarity remain unclear, we speculate that precocial species remain stuck in a simple ecological niche unless they find a way to breed in safer places, which opens the path to provisioning and therefore altriciality.

Finally, our findings imply a modest role at best for socio- and eco-cognitive abilities in the 273 evolution of brain size in birds. We found almost no detectable effect of the cognitive demands of adult social life. We did, however, find weak evidence for effects of ecocognitive parameters independent of parental provisioning that affect the energy balance of 
adults. First, migratory species have smaller brains than resident species (38), indicating that the high energy cost of migration reduces the ability to sustain a large adult brain. Second, the effect of arboreal foraging may be more related to adult survival, as in mammals (39), thus removing a constraint on brain enlargement.

The absence of an effect of the traditionally measured socio- and eco-cognitive variables on relative brain size is puzzling. It may actually reflect a more general problem in comparative cognition, as popular tests often fail to produce a differentiation between species generally thought to show major differences (40). Thus, these tests may not assess those cognitive adaptations that produce fitness benefits by scaffolding critical foraging and predationavoidance skills and improving the ability to provision the young and/or improve survival. Thus, our results suggest we should pay closer attention to cognitive adaptations such as general behavioral flexibility (as enabled by executive functions and domain-general intelligence (41)), including the coordination of parental duties (essentially linked to planning, decision-making, and time management). These cognitive abilities may be expressed behaviorally in avoidance of predation on eggs, nestlings and adults $(42,43)$, in maximization of food intake under everchanging food and weather conditions, or in the socio-cognitive ability to coordinate offspring provisioning (5). For example, some birds

294 flexibly adjust parenting in response to predation risk to themselves and their nestlings (44), as confirmed experimentally (45). However, because these cognitive abilities are not readily estimated in a way that can be compared across species, they are so far not included in comparative analyses of brain size evolution.

To conclude, the amount and duration of parental provisioning is the key to understand brain size evolution in birds. It could also explain the major differences in relative brain size between endotherms and ectotherms (1), which is broadly correlated with the amount of parental provisioning. Moreover, it may also apply to human evolution because we humans have the largest relative brain size among all animals, and parents and other caregivers engage in provisioning children well into adolescence (46). 
We gathered information quantifying parental provisioning and the socio-ecological correlates identified by previous work as influencing brain size in animals. We collected these data from the online version of the Handbooks of the Birds of the World (47), region specific handbooks $(48,49)$, existing published datasets $(32,50-52)$, as well as species

312 specific studies listed in the dataset. Data on brain size were collected from three sources $(9,10,53)$.

315 The following parental provisioning predictors were included: adult body mass, developmental mode, egg mass, clutch size, the time offspring are fed by their parents until nutritional independence, and the number of caretakers. We did not use imputed data

318 based on mean values of related species, which limited our sample size compared to other comparative studies. Adult body mass data were calculated as means if mass of males and females were listed separately. The developmental mode was assessed dichotomously.

321 Precocial species are those which hatch with open eyes and abandon the nest within 2 days after hatching, and here also encompass semi-precocial species (young hatch with open eyes and are soon capable of walking, but they remain in the nest to be fed by parents).

324 Altricial species are those in which young hatch with closed eyes and largely lack feathers and are fed by parents in the nest, and here also encompass semi-altricial species (young hatch with open eyes and are feathered, but remain in the nest to be fed by their parents)

327 (29). Given that this dichotomous split could obscure patterns, we did re-run the main analyses using all four categories (fully precocial, semi-precocial, semi-altricial, fully altricial). Egg mass was either assessed through direct measurements of egg mass, or was calculated

330 based on egg measurements, using the formula by Hoyt (54). For those species where multiple egg dimension measurements were available in the literature, the mean values of all provided measurements were used. For those species where egg dimension or mass data were not available in handbooks, we used information in published data compilations listed in the dataset $(52,55-57)$. Clutch size data corresponded to the median clutch size $(43,57)$. The time young are fed by their parents included both the time parents provision their 336 young in the nest as well as thereafter until young are nutritionally independent from their parents, as reported in handbooks (see above), and published datasets (28). We also included the mean number of caretakers, where mound-nesting species had zero caretakers, species with uniparental care one, species with bi-parental care two, and 
cooperatively breeding species the mean value of caretakers. These data were obtained from handbooks (47), existing datasets $(30,53)$, and species-specific studies listed in the dataset.

Based on previous studies on the drivers of brain size in vertebrates, the following ecological

345 predictors were included: food energy, fiber content of food, number of processing steps required to extract food, foraging substrate, sedentariness, insularity, and climatic predictors. The predictors relating to food were calculated based on an existing database

348 (50). We calculated the mean energy and fiber content of foods per $100 \mathrm{~g}$ from previous studies $(19,58)$, as well as the number of processing steps required to extract food $(59)$. Given that these three predictors are highly correlated (that is, low caloric food usually has a

351 high fiber content and requires only a single processing step), we used a PCA approach and extracted two independent PCs from these predictors (see below). The foraging substrate data were obtained from a published database (51). We categorized species into those that

354 forage arboreally, compared to all other foraging substrates. In mammals, arboreal foraging has been shown to be associated with increased longevity, which in turn allows the evolution of larger brains (39). Sedentariness was assessed based on the maximum

357 movement pattern of a species, separating sedentary species (including local movements) from migratory species (short- and long-distance migrants, altitudinal migrants), combining data from three sources $(9,32,51)$. In addition, we also included data on the insularity of 360 species, distinguishing continental from insular species $(11,51)$. Missing data were directly obtained from the primary sources listed above. Finally, we included data on the climate in the species' geographic range $(60,61)$, using a PCA approach (see below). Values of species

363 with contradicting values in different published datasets were confirmed based on the literature listed above, using the above definitions.

366 The social predictors were also based on previous studies and included social bond strength, group size, and coloniality. Social bond data were based on published data (62), separating species with short bonds during mating only, seasonal bonds, and long-term bonds that 369 extend beyond a single breeding season. The grouping patterns of species outside the breeding season distinguished between asocial species (usually on their own), pair living species (usually in pairs), species that live in small groups (usually 3-30 individuals), and 
large groups (usually more than 30 individuals). The split between small and large groups should capture the difference between personalized groups where group members know each other individually, including family groups (32), and ephemeral and/or anonymous groups. We also included whether species breed singly or whether they breed in colonies.

\section{Analyses}

378 All statistical analyses were carried out in the R 4.0.2 environment (63). The analyses were structured as a series of linear models with increasing complexity, all including phylogenetic relatedness across species (in the form of a phylogenetic correlation matrix based on wellresolved avian phylogenetic trees (35)). For predictors that are expected to be allometrically linked to body mass (brain size, egg mass), the models included their residuals from regressions against body mass. Brain size (the response variable) and adult body mass were log-transformed prior to extracting relative brain sizes. All continuous predictors were mean-centered and scaled to a standard deviation of one, to aid in the interpretation of intercepts and the comparison of effect sizes. The three predictors relating to food (food

387 energy, fiber content, food handling levels) were strongly collinear (S4a Table). Thus, we used a Principal Component analysis in the package psych (64) (using varimax rotation) to reduce these predictors to two uncorrelated components. Based on their loadings, the resulting two components describe the energy content of food and the food handling levels (including the absence of fibers) (S4b Table). Using the same approach, we extracted three uncorrelated components from 14 climatic parameters. PC1 reflects a latitudinal gradient from the tropics to high latitudes. PC2 reflects inter-annual variability. PC3 reflects a gradient from dry, open and highly seasonal environments to stable and closed environments.

We fitted three phylogenetically controlled mixed models that assessed the dependence of relative brain size on provisioning predictors (model 1), eco-social predictors (model 2), and a combination of both (model 3). Each model included a set of main effects and first-order interactions with meaningful biological interpretation (see S1-3 Tables for a full list of predictors and interactions in each of the models). Since the size of models (both in terms of data and numbers of predictors) prevented a full search of all predictor combinations via selection based on information criteria (IC), we conducted backward simplification of 
models, removing non-significant interactions (starting with the ones having the largest prediction error). To remain conservative, we did not remove non-significant main effects. Backward selection has been shown to perform well in comparison to IC-based model selection in similar contexts (65), and is robust in cases where the number of individual observations exceeds several fold the number of estimated predictors, as is the case here. We report final outputs of the most parsimonious models (Fig 1, S1-3 Tables). All models were fitted using an MCMC-based mixed modelling approach using the package

411 MCMCgImm (33). We used chains of 50'000 iterations, with the first 10'000 iterations discarded as burn-ins and thinned every 40 iterations. Inspection of the final MCMC samples did not show any sign of autocorrelation. All effective sample sizes were close to the actual

414 numbers of sampled draws from predictors' posteriors. In all models, inverse-gamma priors were used for residual variances (parametrized as inverse-Wishart with $V=1$ and $v=0.002$ ). The prior for phylogenetic effect was formed as a weakly informative half-Cauchy density

417 (parameter expanded priors with $V=1, v=1, \alpha_{\mu}=0$ and $\alpha_{V}=10^{\prime} 000$ ). Priors for fixed effects were left as default (Gaussian densities with $\mu=0$ and large variance). Using a modification of the variance inflation factor (VIF) analysis adjusted to the phylogenetic comparative mixed model used, we verified that none of the other predictors were significantly collinear, as all VIF values were $<2$ (S5 Table).

423 The necessity of complete information on all predictors reduced the sample size of the main models to 1,176 species. Thus, we fitted additional models excluding those predictors that most strongly limited our sample size: excluding duration of parental provisioning $(N=1,458$ species); excluding duration of parental provisioning and social grouping ( $N=1,594$ species). Both models recaptured the patterns observed in the full model (S2 Table), confirming that our sample was not biased by limited data (S3a-b Tables).

Subsequent to the phylogenetically controlled mixed models, we conducted phylogenetic path analyses to assess the causal links among the predictors included in parental provisioning, the eco-social and the combined model. Briefly, for each model we defined a set of $d$-separation statements $(34,37,66)$, describing a hypothesis represented by a directed acyclic graph, linking all involved predictors with causal links. We included wellestablished developmental and eco-social patterns in all models, but also added biologically 
plausible relationships that were varied across the different models. The sequence of models considered reflects hypotheses related to brain size predictors, as outlined in S2-4

438 Figs. The statements were then represented as sets of linear mixed models and fitted using a phylogenetic comparative framework implemented in the ASReml-R package (67). In models involving binary responses (e.g., precocial/altricial), we used generalized linear

441 mixed models with probit link function to fit models, which makes their regression coefficients directly comparable with standardized regression coefficients from general linear models for continuous predictors. Since all continuous predictors were scaled to unit

444 standard deviation, results for categorical predictors can be interpreted as standardized Cohen's d effect sizes, and thus, can be directly compared with continuous standardized regression coefficients. The best-fitting hypothesis in each model set was determined via

447 comparisons of $\mathrm{ClCc}$ (corrected Fisher's C Information Criterion, a path analysis analogue of AICc (37)). In the parental provisioning and eco-social model, the best model was clearly supported over the alternatives ( $\triangle \mathrm{ClC} c>2$ for top models). In the combined model, two

450 models were clearly supported over the alternatives, but were conceptually identical (S6 Table).

\section{Code availability}

Code used for the analyses and plotting the figures are available from S.M.D. upon request.

\section{Data availability}

The data are provided in a supplement.

\section{References}

1. H. J. Jerison, Evolution of the Brain and Intelligence (Academic Press, New York, 1973).

462 2. S. M. Reader, Y. Hager, K. N. Laland, The evolution of primate general and cultural intelligence. Philosophical Transactions of the Royal Society B: Biological Sciences 366, 1017-1027 (2011).

465 3. R. O. Deaner, K. Isler, J. Burkart, C. Van Schaik, Overall brain size, and not encephalization quotient, best predicts cognitive ability across non-human primates. Brain, behavior and evolution 70, 115-124 (2007).

468 4. S. E. Overington, J. Morand-Ferron, N. J. Boogert, L. Lefebvre, Technical innovations drive the relationship between innovativeness and residual brain size in birds. Animal Behaviour 78, 1001-1010 (2009).

471 5. R. I. Dunbar, S. Shultz, Evolution in the social brain. Science 317, 1344-1347 (2007). 
6. S. Shultz, R. Dunbar, Encephalization is not a universal macroevolutionary phenomenon in mammals but is associated with sociality. Proceedings of the National Academy of Sciences 107, 21582-21586 (2010).

7. R. I. Dunbar, The social brain hypothesis. Evolutionary Anthropology: Issues, News, and Reviews: Issues, News, and Reviews 6, 178-190 (1998).

477 8. S. Shultz, R. I. Dunbar, Social bonds in birds are associated with brain size and contingent on the correlated evolution of life-history and increased parental investment. Biological Journal of the Linnean Society 100, 111-123 (2010).

480 9. F. Sayol et al., Environmental variation and the evolution of large brains in birds. Nature Communications 7, 13971 (2016).

10. T. S. Fristoe, C. A. Botero, Alternative ecological strategies lead to avian brain size

11. F. Sayol, P. A. Downing, A. N. Iwaniuk, J. Maspons, D. Sol, Predictable evolution towards larger brains in birds colonizing oceanic islands. Nature Communications $\mathbf{9}$, 2820 (2018).

12. T. S. Fristoe, A. N. Iwaniuk, C. A. Botero, Big brains stabilize populations and facilitate colonization of variable habitats in birds. Nature ecology \& evolution 1, 1706-1715 (2017).

13. P. Minias, P. Podlaszczuk, Longevity is associated with relative brain size in birds. Ecology and evolution 7, 3558-3566 (2017).

14. X. Yu et al., Large-brained frogs mature later and live longer. Evolution 72, 1174-1183 (2018).

15. N. L. Barrickman, M. L. Bastian, K. Isler, C. P. van Schaik, Life history costs and benefits of encephalization: a comparative test using data from long-term studies of primates in the wild. Journal of human evolution 54, 568-590 (2008).

16. A. L. Bauernfeind et al., Aerobic glycolysis in the primate brain: reconsidering the 1167 (2014).

17. J. W. Mink, R. J. Blumenschine, D. B. Adams, Ratio of central nervous system to body metabolism in vertebrates: its constancy and functional basis. American Journal of Physiology-Regulatory, Integrative and Comparative Physiology 241, R203-R212 (1981).

504 18. L. C. Aiello, P. Wheeler, The expensive-tissue hypothesis: the brain and the digestive system in human and primate evolution. Current anthropology 36, 199-221 (1995).

19. K. Isler, C. van Schaik, Costs of encephalization: the energy trade-off hypothesis

20. J. T. van Woerden, E. P. Willems, C. P. van Schaik, K. Isler, Large brains buffer energetic effects of seasonal habitats in catarrhine primates. Evolution: International Journal of Organic Evolution 66, 191-199 (2012).

21. S. A. Heldstab, K. Isler, C. P. van Schaik, Hibernation constrains brain size evolution in mammals. J. Evol. Biol. 31, 1582-1588 (2018).

$51322 . \quad$ R. D. Martin, Relative brain size and basal metabolic rate in terrestrial vertebrates. Nature 293, 57-60 (1981).

23. R. D. Martin, Scaling of the mammalian brain: the maternal energy hypothesis.

$516 \quad$ Physiology 11, 149-156 (1996).

24. R. A. Barton, I. Capellini, Maternal investment, life histories, and the costs of brain growth in mammals. Proceedings of the National Academy of Sciences 108, 61696174 (2011). 
25. M. Tsuboi et al., Comparative support for the expensive tissue hypothesis: big brains are correlated with smaller gut and greater parental investment in Lake Tanganyika cichlids. Evolution 69, 190-200 (2015).

26. C. G. Mull, K. E. Yopak, N. K. Dulvy, Maternal investment, ecological lifestyle, and brain evolution in sharks and rays. The American Naturalist 195, 1056-1069 (2020).

525 27. A. Portmann, Etudes sur la cérébralisation chez les oiseaux. III Cérébralisation et mode ontogénétique. Alauda 15, 1-171 (1947).

28. A. N. Iwaniuk, J. E. Nelson, Developmental differences are correlated with relative brain size in birds: a comparative analysis. Canadian Journal of Zoology 81, 19131928 (2003).

29. J. M. Starck, R. E. Ricklefs, Avian growth and development: evolution within the

altricial-precocial spectrum (Oxford University Press, 1998).

30. A. Cockburn, Prevalence of different modes of parental care in birds. Proceedings of the Royal Society B-Biological Sciences 273, 1375-1383 (2006).

534 31. A. L. Pigot et al., Macroevolutionary convergence connects morphological form to ecological function in birds. Nature Ecology \& Evolution 4, 230-239 (2020).

32. M. Griesser, S. M. Drobniak, S. Nakagawa, C. A. Botero, Family living sets the stage e2000483 (2017).

33. J. D. Hadfield, MCMC methods for multi-response generalized linear mixed models:

34. A. M. Hardenberg, A. Gonzalez-Voyer, Disentangling evolutionary cause-effect
34. relationships with phylogenetic confirmatory path analysis. Evolution: International Journal of Organic Evolution 67, 378-387 (2013).

35. W. Jetz, G. H. Thomas, J. B. Joy, K. Hartmann, A. O. Mooers, The global diversity of birds in space and time. Nature 491, 444-448 (2012).

546 36. R. O. Prum et al., A comprehensive phylogeny of birds (Aves) using targeted nextgeneration DNA sequencing. Nature 526, 569 (2015).

37. B. Shipley, The AIC model selection method applied to path analytic models

38. O. Vincze, Light enough to travel or wise enough to stay? Brain size evolution and migratory behavior in birds. Evolution 70, 2123-2133 (2016).

39. C. P. van Schaik, R. O. Deaner, Life history and brain evolution. Animal social complexity: intelligence, culture, and individualized societies (eds FBM de Waal \& PL Tyack), 1-25 (2003).

555 40. C. Fichtel, K. Dinter, P. M. Kappeler, The lemur baseline: how lemurs compare to monkeys and apes in the Primate Cognition Test Battery. PeerJ 8, e10025 (2020).

41. J. M. Burkart, M. N. Schubiger, C. P. van Schaik, The evolution of general intelligence.

42. T. E. Martin, J. V. Briskie, "Predation on Dependent Offspring A Review of the Consequences for Mean Expression and Phenotypic Plasticity in Avian Life History Traits" in Year in Evolutionary Biology 2009. (Blackwell Publishing, Oxford, 2009), vol. 1168, pp. 201-217.

43. M. Valcu, J. Dale, M. Griesser, S. Nakagawa, B. Kempenaers, Global gradients of avian longevity support the classic evolutionary theory of ageing. Ecography 37, 930-938 (2014).

44. S. L. Lima, Predators and the breeding bird: behavioral and reproductive flexibility under the risk of predation. Biol. Rev. 84, 485-513 (2009). 
45. S. Eggers, M. Griesser, J. Ekman, Predator-induced plasticity in nest visitation rates in the Siberian jay (Perisoreus infaustus). Behavioral Ecology 16, 309-315 (2005).

570 46. H. Kaplan, K. Hill, J. Lancaster, A. M. Hurtado, A theory of human life history evolution: Diet, intelligence, and longevity. Evolutionary Anthropology: Issues, News, and Reviews: Issues, News, and Reviews 9, 156-185 (2000).

573 47. J. Del Hoyo, A. Elliot, J. Sargatal, D. A. Christie, Handbook of the Birds of the World ( Lynx Editions, Barcelona, 2011).

48. P. A. R. Hockey, W. J. J. Dean, P. G. Ryan, Roberts Birds of Southern Africa (Trustees

49. P. J. Higgins, S. Marchant, J. M. Peter, S. Cowling, J. Davies, Handbook of Australian, New Zealand \& Antarctic Birds (Oxford University Press, 2007).

579 50. H. Wilman et al., EltonTraits 1.0: Species-level foraging attributes of the world's birds and mammals. Ecology 95, 2027-2027 (2014).

51. J. A. Tobias, A. L. Pigot, Integrating behaviour and ecology into global biodiversity conservation strategies. Philosophi
Sciences 374, 20190012 (2019).

52. T. Lislevand, J. Figuerola, T. Székely, Avian body sizes in relation to fecundity, mating system, display behavior, and resource sharing. Ecology 88, 1605-1605 (2007).

53. S. Graber (2017) Social and ecological aspects of brain size evolution: a comparative approach. in Department of Anthropology (University of Zurich, Zurich), p 182.

54. D. F. Hoyt, Practical methods of estimating volume and fresh weight of bird eggs. The Auk 96, 73-77 (1979).

55. K. Schläpfer, The colorful eggs of the tinamous (Published by author, Engelburg,

Switzerland, 2017).

56. J.-Y. Juang et al., The avian egg exhibits general allometric invariances in mechanical design. Scientific Reports 7, 1-11 (2017).

594 57. C. Brown, P. Bridgeford, S. Braine, M. Paxton, W. Versfeld, Breeding data on the birds of Namibia: laying months, colony and clutch sizes and egg measurements. Biodiversity Observations, 92-196 (2015).

597 58. P. Langer, Lactation, weaning period, food quality, and digestive tract differentiations in eutheria. Evolution 57, 1196-1215 (2003).

59. C. Schuppli, S. M. Graber, K. Isler, C. P. van Schaik, Life history, cognition and the

evolution of complex foraging niches. Journal of Human Evolution 92, 91-100 (2016).

60. U. Roll et al., The global distribution of tetrapods reveals a need for targeted reptile conservation. Nature Ecology \& Evolution 1, 1677-1682 (2017).

603 61. G. Murali, R. Gumbs, S. Meiri, U. Roll, Global determinants and conservation of evolutionary and geographic rarity in land vertebrates. Science advances 7 , eabe5582 (2021).

606 62. J. A. Tobias et al., Territoriality, social bonds, and the evolution of communal signaling in birds. Frontiers in Ecology and Evolution 4, 74 (2016).

63. R Core Team (2016) R: A language and environment for statistical computing. (R

6oundation for Statistical Computing, Vienna, Austria. ).
W. Revelle (2012) Procedures for psychological, psychometric, and personality Research. R Package Version 1.9.12. (Evanston, Illinois).

612 65. P. A. Murtaugh, Performance of several variable-selection methods applied to real ecological data. Ecology letters 12, 1061-1068 (2009).

66. B. Shipley, Confirmatory path analysis in a generalized multilevel context. Ecology 90, 363-368 (2009). 
67. D. Butler (2019) Asreml: Fits the linear mixed model. R package version 4.1.0.110. (VSNi, Hemel Hempstead, UK).

\section{Acknowledgements}

We thank all field biologists who collected all the natural history data underlying this study.

621 We thank Uri Roll for sharing climatic data.

\section{Funding}

624 M.G.: Heisenberg Grant nr. GR 4650/2-1 by the German Research Foundation DFG.

S.M.D: Polish National Science Centre, grant no. UMO-2015/18/E/NZ8/00505 and Australian

Research Council, DECRA award no. DE180100202.

627 C.P.S: University of Zurich.

\section{Author contributions}

630 M.G. contributed to acquisition of funding, conceptualizing, data collection, data analyses, interpretation of the data, drafting the manuscript.

S.M.D. contributed the data analyses, interpretation of the data.

633 S.M.G. contributed to data collection, data analyses, revising the manuscript.

C.P. S. contributed to acquisition of funding, conceptualizing, interpretation of the data, drafting the manuscript.

636

\section{Competing interests}

None.

\section{Materials \& Correspondence}

M.G. 


\section{Supporting Information}

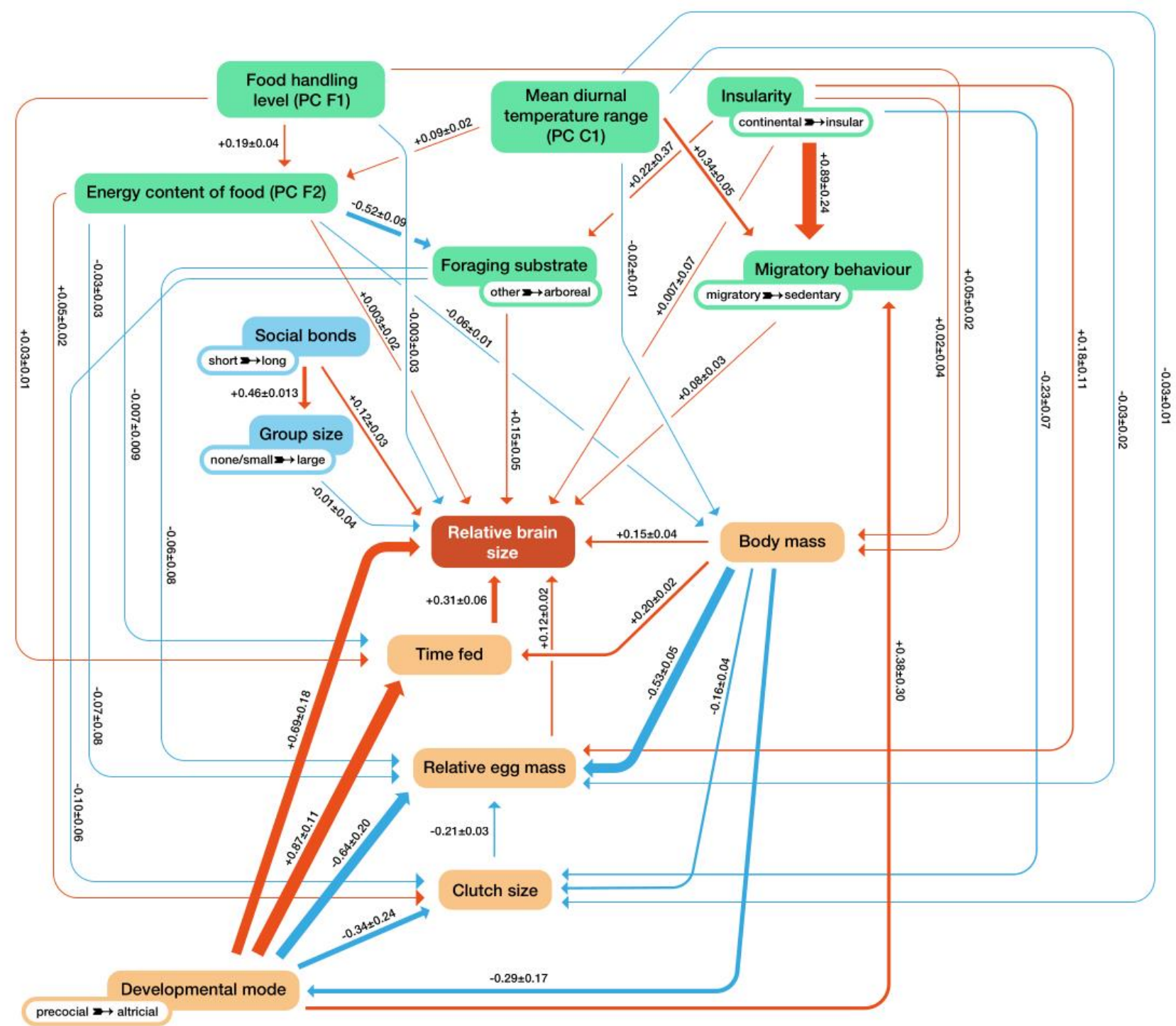

S1 Fig. Phylogenetic associations among parental provisioning (orange), ecological and social

bird species). Arrow thickness and numeric values show the strength of the association, arrow color its direction (orange: positive, blue: negative). 


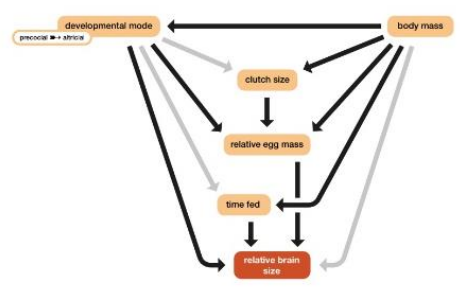

model_A1

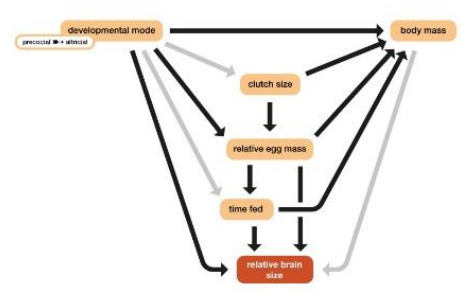

model_A4

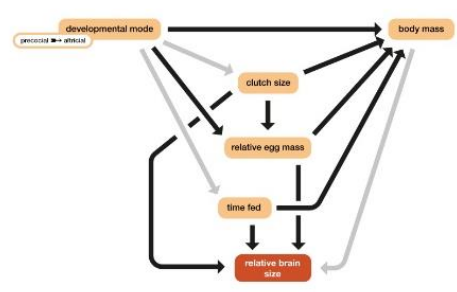

model_A7

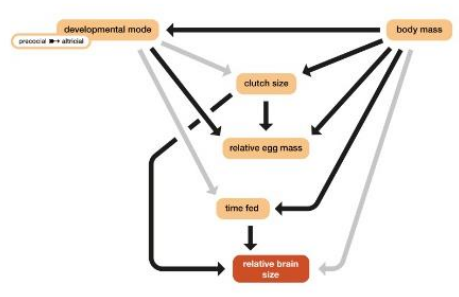

model_A10

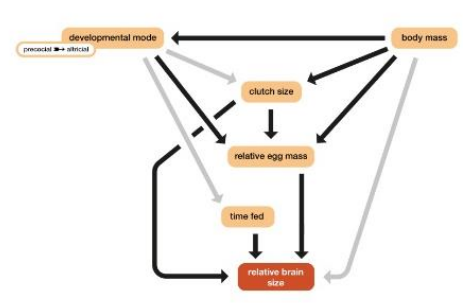

model_A13

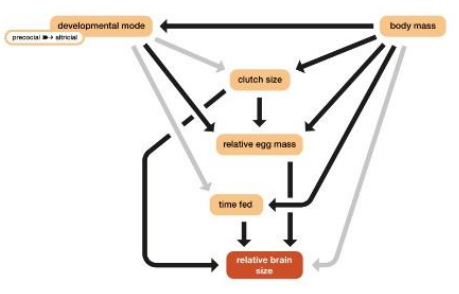

model_A2

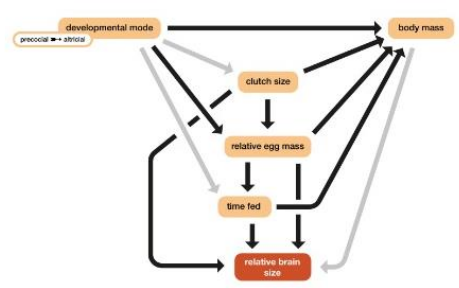

model_A5

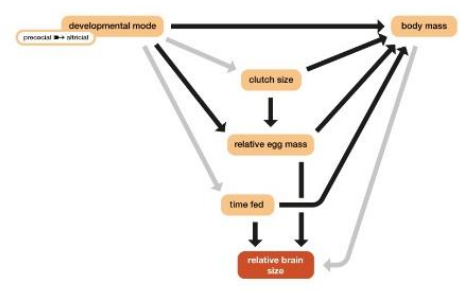

model_A8

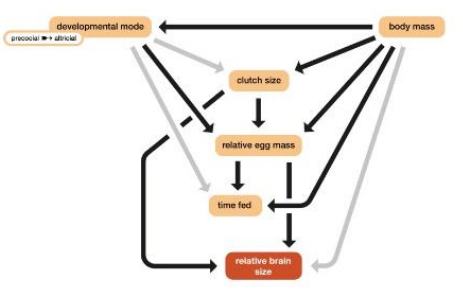

model_A11

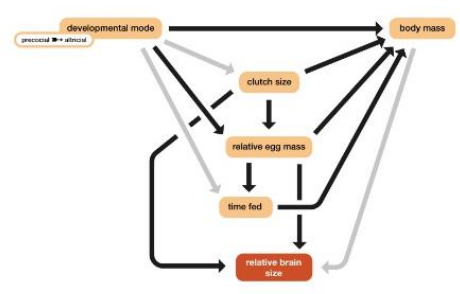

model_A14

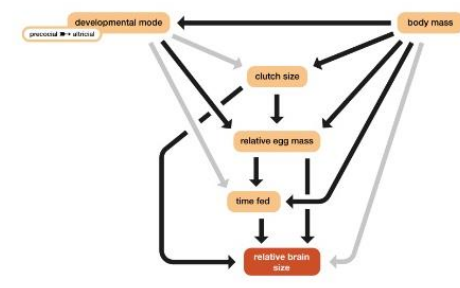

model_A3

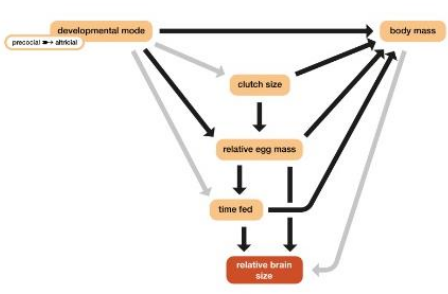

model_A6

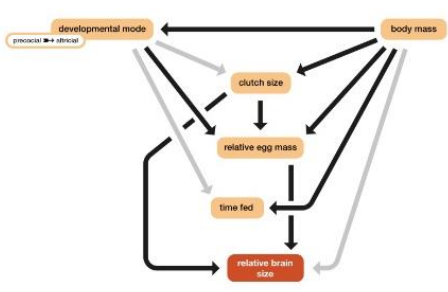

model_A9

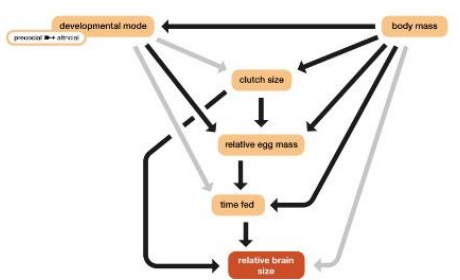

model_A12

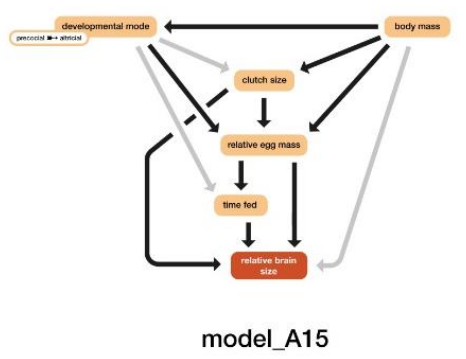
analyses, arranged by increasing CCIC. Grey arrows indicate relationships retained in all models, black arrows indicate relationships that varied between different models. 


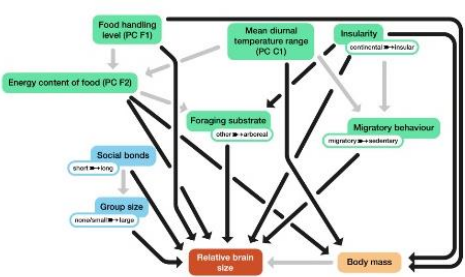

model_E1

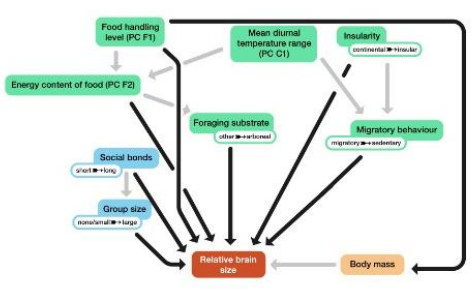

model_E4

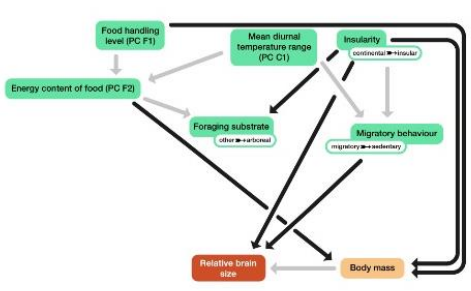

model_E7

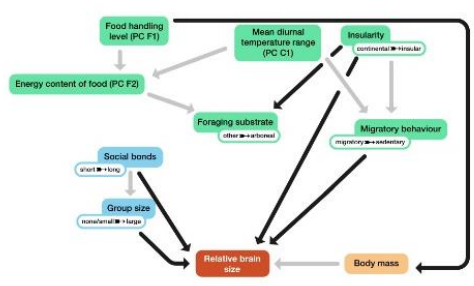

model_E10

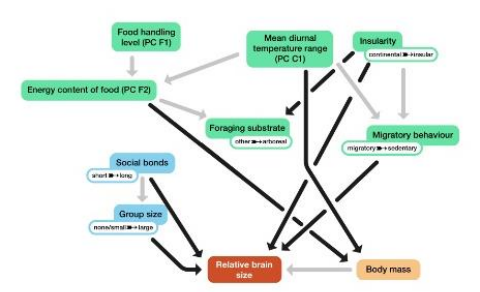

model_E13

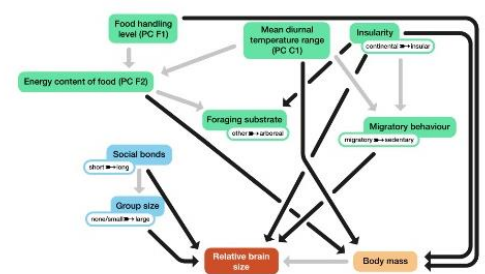

model_E2

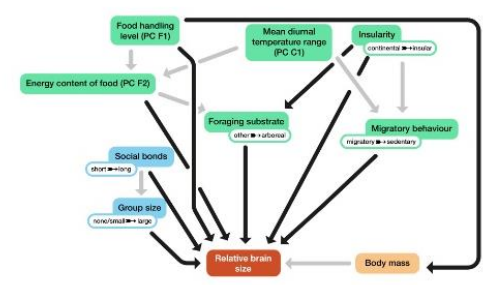

model_E5

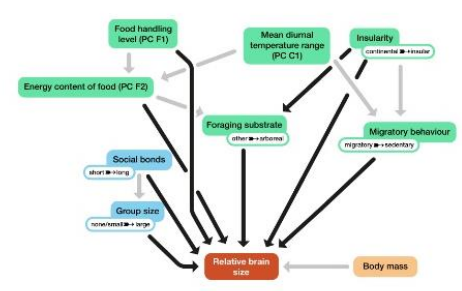

model_E8

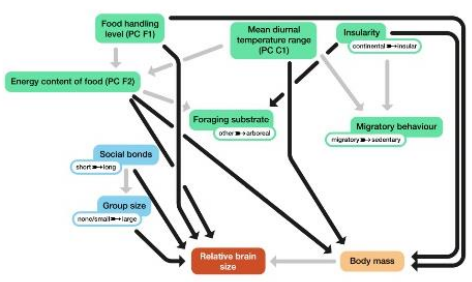

model_E11

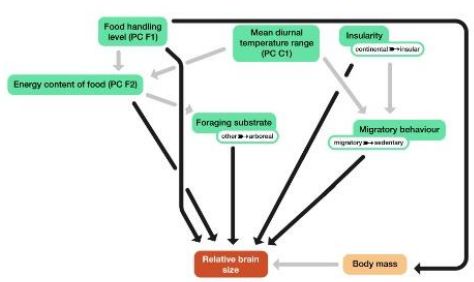

model_E14

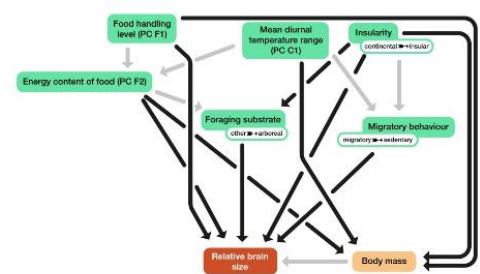

model_E3

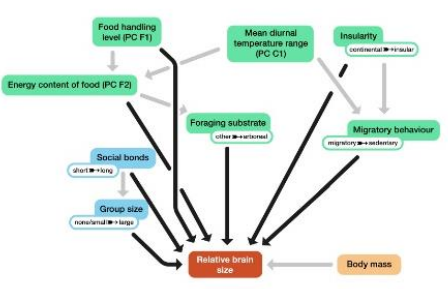

model_E6

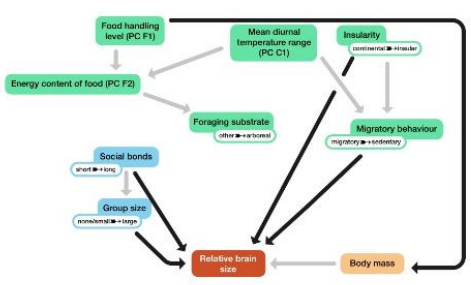

model_E9

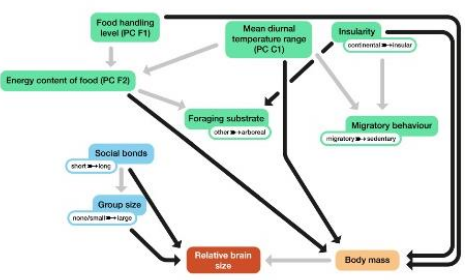

model_E12

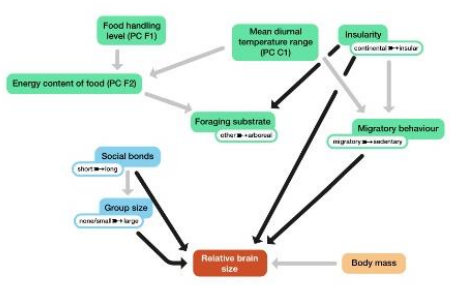

model_E15

S3 Fig. Network topologies of the top 15 eco-social models of the phylogenetic path analyses,

arranged by increasing cCIC. Grey arrows indicate relationships retained in all models, black arrows indicate relationships that varied between different models. 


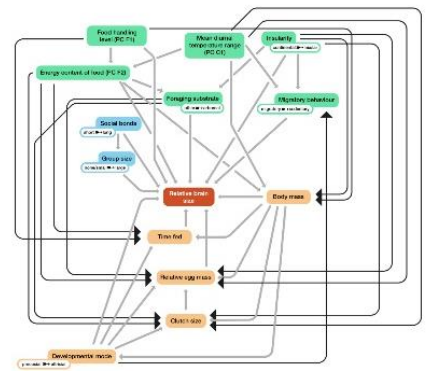

model_C1

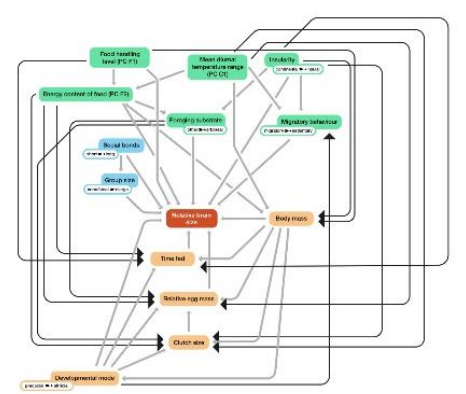

model_C4

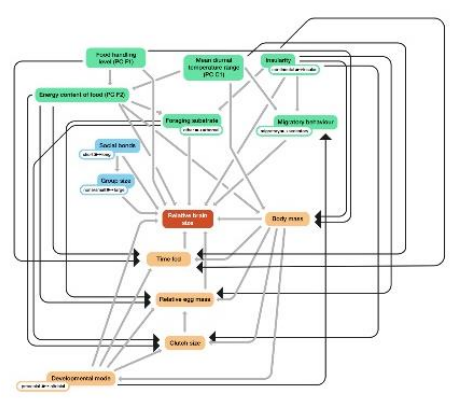

model_C7

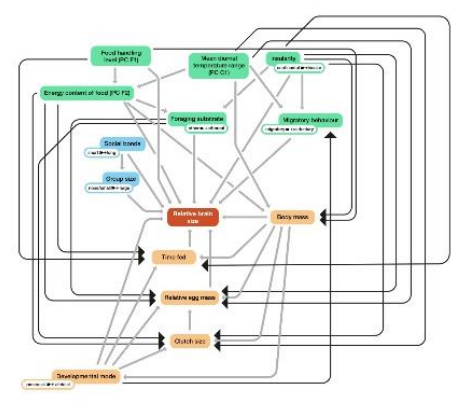

model_C2

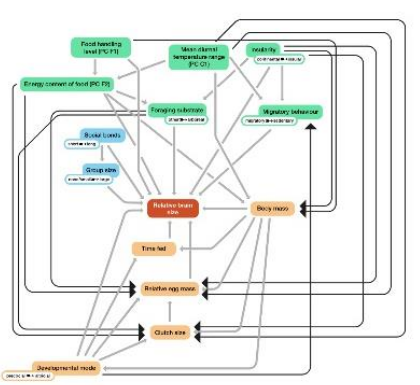

model_C5

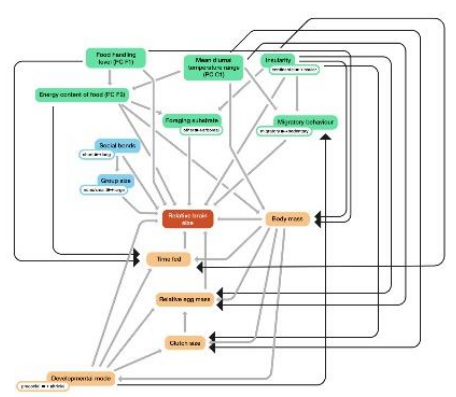

model_C8

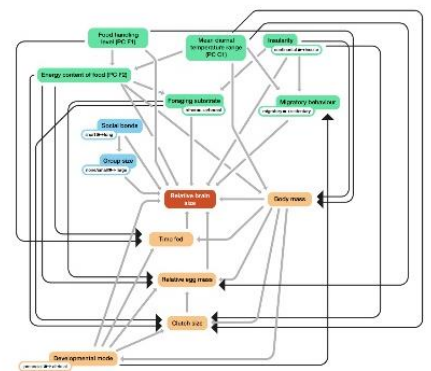

model_C3

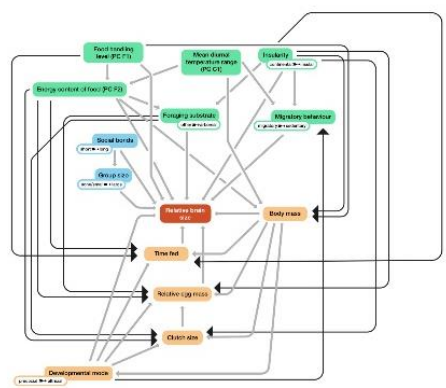

model_C6

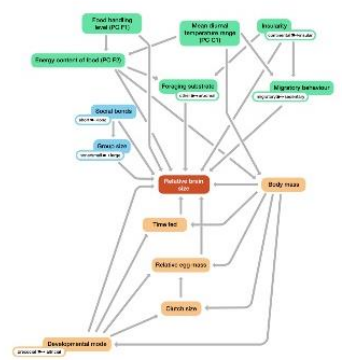

model_C9

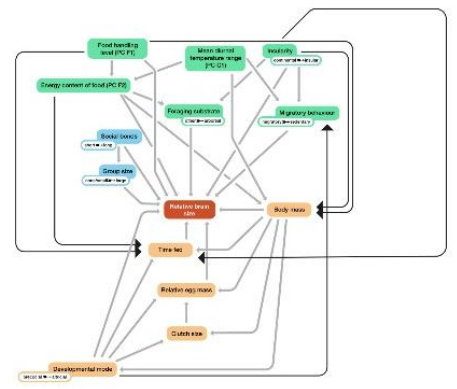

model_C10

S4 Fig. Network topologies of all 10 combined models of the phylogenetic path analyses, arranged relationships that varied between different models. 
bioRxiv preprint doi: https://doi.org/10.1101/2021.12.19.470191; this version posted December $21,2021$. The copyright holder for this preprint (which was not certified by peer review) is the author/funder, who has granted bioRxiv a license to display the preprint in perpetuity. It is made available under aCC-BY-NC-ND 4.0 International license.

S1a-c Table. Phylogenetically controlled mixed models in MCMCgImm(33) assessing the effect on absolute brain size in birds ( $\mathrm{N}=1,176$ species) of a) parental provisioning predictors, b) eco-social predictors, and c) both combined.

\begin{tabular}{|c|c|c|c|c|c|}
\hline & Predictor & Post. mean & lower $\cdot$ upper $95 \% \mathrm{Cl}$ & $\mathrm{N}$ & $\mathrm{p} \mathrm{MCMC}$ \\
\hline \multirow{14}{*}{$\begin{array}{l}\text { a) Parental } \\
\text { investment } \\
\text { model }\end{array}$} & Intercept & -0.30 & $-0.46 \cdot-0.11$ & 1000 & $<0.001$ \\
\hline & Mass & -0.03 & $-0.07 \cdot 0.01$ & 893 & 0.11 \\
\hline & Development mode (precocial vs altricial) & 0.12 & $-0.02 \cdot 0.25$ & 1000 & 0.10 \\
\hline & Clutch size & -0.07 & $-0.09 \cdot-0.04$ & 1000 & $<0.001$ \\
\hline & Residual egg mass & 0.09 & $0.04 \cdot 0.14$ & 1000 & 0.002 \\
\hline & Time fed & 0.09 & $0.04 \cdot 0.14$ & 1000 & $<0.001$ \\
\hline & Number of caretakers & 0.00 & $-0.01 \cdot 0.01$ & 1000 & 0.51 \\
\hline & Mass $\mathrm{x}$ development mode & 0.18 & $0.13 \cdot 0.24$ & 1000 & $<0.001$ \\
\hline & Mass $\mathrm{x}$ clutch size & 0.02 & $0.01 \cdot 0.04$ & 1000 & 0.008 \\
\hline & Mass $\mathrm{x}$ residual egg mass & 0.07 & $0.03 \cdot 0.11$ & 1000 & $<0.001$ \\
\hline & Development mode $x$ clutch size & 0.09 & $0.06 \cdot 0.13$ & 1000 & $<0.001$ \\
\hline & Development mode $\mathrm{x}$ residual egg mass & 0.19 & $0.12 \cdot 0.28$ & 1087 & $<0.001$ \\
\hline & Development mode $x$ time fed & 0.07 & $0.00 \cdot 0.16$ & 1000 & 0.051 \\
\hline & Residual egg mass $x$ clutch size & 0.09 & $0.07 \cdot 0.11$ & 1000 & $<0.001$ \\
\hline \multirow{19}{*}{$\begin{array}{l}\text { b) Eco-social } \\
\text { model }\end{array}$} & Intercept & -0.4 & $-0.57 \cdot-0.22$ & 1155 & $<0.001$ \\
\hline & Mass & 0.98 & $0.95 \cdot 1$ & 1000 & $<0.001$ \\
\hline & Foraging substrate (others vs arboreal) & 0.11 & $0.06 \cdot 0.15$ & 954 & $<0.001$ \\
\hline & Migratory behavior (sedentary vs migratory) & 0.05 & $0.03 \cdot 0.07$ & 1190 & $<0.001$ \\
\hline & Energy content of food (PC) & 0.00 & $-0.01 \cdot 0.01$ & 1000 & 0.92 \\
\hline & Food handling level (PC) & 0.00 & $-0.02 \cdot 0.02$ & 1000 & 0.93 \\
\hline & Insularity (continental vs insular) & 0.00 & $-0.04 \cdot 0.06$ & 1000 & 0.89 \\
\hline & Mean diurnal temperature range $(\mathrm{PC})$ & 0.00 & $0.00 \cdot 0.01$ & 1000 & 0.33 \\
\hline & Annual temperature and rainfall (PC) & -0.01 & $-0.03 \cdot 0.00$ & 1000 & 0.064 \\
\hline & Climatic seasonality (PC) & 0.00 & $-0.01 \cdot 0.01$ & 1000 & 0.88 \\
\hline & Short vs seasonal social bonds & 0.03 & $-0.01 \cdot 0.09$ & 1000 & 0.18 \\
\hline & Short vs long-term social bonds & 0.07 & $0.02 \cdot 0.13$ & 1000 & 0.002 \\
\hline & Colonial vs solitary breeding & 0.00 & $-0.02 \cdot 0.02$ & 1131 & 0.82 \\
\hline & Asocial vs pair living & -0.03 & $-0.06 \cdot 0.01$ & 1000 & 0.11 \\
\hline & Asocial vs small groups & -0.02 & $-0.05 \cdot 0.02$ & 1000 & 0.35 \\
\hline & Asocial vs large groups & 0.00 & $-0.03 \cdot 0.03$ & 1288 & 0.96 \\
\hline & Mass $\mathrm{x}$ foraging substrate & 0.1 & $0.06 \cdot 0.14$ & 861 & $<0.001$ \\
\hline & Mass $\mathrm{x}$ sedentariness & -0.03 & $-0.05 \cdot-0.01$ & 1000 & 0.01 \\
\hline & Mass $x$ energy content of food (PC) & 0.02 & $0.01 \cdot 0.03$ & 1000 & 0.004 \\
\hline \multirow{31}{*}{$\begin{array}{l}\text { c) Combined } \\
\text { model }\end{array}$} & Intercept & -0.36 & $-0.55 \cdot-0.18$ & 1000 & $<0.001$ \\
\hline & Mass & 0.94 & $0.90 \cdot 0.97$ & 901 & $<0.001$ \\
\hline & Development mode (precocial vs altricial) & 0.17 & $0.05 \cdot 0.29$ & 1000 & 0.01 \\
\hline & Clutch size & -0.06 & $-0.09 \cdot-0.04$ & 1000 & $<0.001$ \\
\hline & Residual egg mass & 0.1 & $0.05 \cdot 0.14$ & 1000 & $<0.001$ \\
\hline & Time fed & 0.06 & $0.01 \cdot 0.11$ & 1000 & 0.018 \\
\hline & Number of caretakers & 0.00 & $-0.01 \cdot 0.01$ & 1000 & 0.67 \\
\hline & Mass $\mathrm{x}$ development mode & 0.16 & $0.11 \cdot 0.21$ & 891 & $<0.001$ \\
\hline & Mass $x$ clutch size & 0.02 & $0.00 \cdot 0.03$ & 1000 & 0.016 \\
\hline & Mass $\mathrm{x}$ residual egg mass & 0.06 & $0.03 \cdot 0.09$ & 1000 & $<0.001$ \\
\hline & Development mode $x$ clutch size & 0.11 & $0.08 \cdot 0.15$ & 1000 & $<0.001$ \\
\hline & Development mode $\mathrm{x}$ residual egg mass & 0.17 & $0.10 \cdot 0.24$ & 1000 & $<0.001$ \\
\hline & Development mode $x$ time fed & 0.07 & $0.00 \cdot 0.15$ & 1000 & 0.078 \\
\hline & Residual egg mass $x$ clutch size & 0.08 & $0.06 \cdot 0.10$ & 1108 & $<0.001$ \\
\hline & Foraging substrate (others vs arboreal) & 0.09 & $0.05 \cdot 0.14$ & 1000 & $<0.001$ \\
\hline & Migratory behavior (sedentary vs migratory) & 0.04 & $0.02 \cdot 0.06$ & 1079 & $<0.001$ \\
\hline & Energy content of food (PC) & 0.01 & $0.00 \cdot 0.03$ & 1179 & 0.056 \\
\hline & Food handling level (PC) & 0.02 & $-0.01 \cdot 0.04$ & 972 & 0.22 \\
\hline & Insularity (continental vs insular) & 0.01 & $-0.03 \cdot 0.06$ & 1000 & 0.68 \\
\hline & Mean diurnal temperature range $(\mathrm{PC})$ & 0.00 & $-0.01 \cdot 0.01$ & 1000 & 0.64 \\
\hline & Annual temperature and rainfall (PC) & -0.01 & $-0.02 \cdot 0.00$ & 1000 & 0.23 \\
\hline & Climatic seasonality (PC) & 0.00 & $-0.01 \cdot 0.01$ & 1000 & 0.53 \\
\hline & Short vs seasonal social bonds & -0.01 & $-0.06 \cdot 0.04$ & 1000 & 0.77 \\
\hline & Short vs long-term social bonds & 0.02 & $-0.03 \cdot 0.07$ & 1000 & 0.39 \\
\hline & Colonial vs solitary breeding & -0.01 & $-0.03 \cdot 0.02$ & 1000 & 0.59 \\
\hline & Asocial vs pair living & -0.03 & $-0.06 \cdot 0.00$ & 1098 & 0.10 \\
\hline & Asocial vs small groups & -0.02 & $-0.05 \cdot 0.01$ & 1000 & 0.27 \\
\hline & Asocial vs large groups & 0.00 & $-0.03 \cdot 0.02$ & 1215 & 0.78 \\
\hline & Mass $\mathrm{x}$ foraging substrate & 0.06 & $0.02 \cdot 0.10$ & 1000 & 0.008 \\
\hline & Mass $\mathrm{x}$ sedentariness & -0.03 & $-0.05 \cdot-0.01$ & 1000 & $<0.001$ \\
\hline & Mass $x$ energy content of food (PC) & 0.01 & $0.00 \cdot 0.02$ & 1000 & 0.13 \\
\hline
\end{tabular}


bioRxiv preprint doi: https://doi.org/10.1101/2021.12.19.470191; this version posted December $21,2021$. The copyright holder for this preprint (which was not certified by peer review) is the author/funder, who has granted bioRxiv a license to display the preprint in perpetuity. It is made available under aCC-BY-NC-ND 4.0 International license.

\begin{tabular}{llllr} 
Developmental mode $x$ food handling level (PC) & -0.05 & $-0.08 \cdot-0.01$ & 900 & 0.018 \\
Clutch size $x$ energy content of food (PC) & -0.01 & $-0.02 \cdot 0.00$ & 1000 & 0.04 \\
Clutch size $x$ food handling level (PC) & -0.01 & $-0.03 \cdot 0.00$ & 1000 & 0.014 \\
\hline
\end{tabular}

Significant predictors are highlighted in bold. Post. mean $=$ mean of the posterior distribution of a

672 parameter, $\mathrm{Cl}=$ posterior credibility interval, $\mathrm{N}=$ effective sample size (corrected for $\mathrm{MCMC}$

timeseries autocorrelation), $\mathrm{p}$ MCMC $=$ P-value. The Principal Component analyses (PCAs) of climatic and food parameters are shown in S4 Table. 
bioRxiv preprint doi: https://doi.org/10.1101/2021.12.19.470191; this version posted December $21,2021$. The copyright holder for this preprint (which was not certified by peer review) is the author/funder, who has granted bioRxiv a license to display the preprint in perpetuity. It is made available under aCC-BY-NC-ND 4.0 International license.

675 S2a-d Table. Phylogenetically controlled mixed models in MCMCgImm(33) assessing the effect on relative brain size in birds (model a-c: $\mathrm{N}=\mathbf{1 , 1 7 6}$ species, model $\mathrm{d}$ : $\mathrm{N}=\mathbf{8 8 6}$ species) of a) parental provisioning predictors, b) eco-social predictors, c) both combined, and d) both combined and including longevity.

\begin{tabular}{|c|c|c|c|c|}
\hline & Predictor & Post. mean & lower - upper $95 \% \mathrm{Cl}$ & $\mathrm{p} \mathrm{MCMC}$ \\
\hline \multirow{14}{*}{$\begin{array}{l}\text { a) Parental } \\
\text { investment } \\
\text { model }\end{array}$} & Intercept & -0.29 & $-0.49 \cdot-0.10$ & 1 \\
\hline & Mass & -0.03 & $-0.07 \cdot 0.01$ & 0.02 \\
\hline & Development mode (precocial vs altricial) & 0.11 & $-0.02 \cdot 0.24$ & 0.04 \\
\hline & Clutch size & -0.07 & $-0.10 \cdot-0.04$ & 1 \\
\hline & Residual egg mass & 0.10 & $0.04 \cdot 0.15$ & 1 \\
\hline & Time fed & 0.09 & $0.04 \cdot 0.14$ & 1 \\
\hline & Number of caretakers & 0.00 & $-0.01 \cdot 0.01$ & 0 \\
\hline & Mass $\mathrm{x}$ development mode & 0.19 & $0.13 \cdot 0.24$ & 1 \\
\hline & Mass $\mathrm{x}$ clutch size & 0.02 & $0.01 \cdot 0.04$ & 1 \\
\hline & Mass $\mathrm{x}$ residual egg mass & 0.07 & $0.03 \cdot 0.10$ & 1 \\
\hline & Development mode $x$ clutch size & 0.09 & $0.05 \cdot 0.13$ & 1 \\
\hline & Development mode $\mathrm{x}$ residual egg mass & 0.19 & $0.11 \cdot 0.27$ & 1 \\
\hline & Development mode $x$ time fed & 0.07 & $-0.01 \cdot 0.15$ & 0 \\
\hline & Residual egg mass $x$ clutch size & 0.09 & $0.06 \cdot 0.11$ & 1 \\
\hline \multirow{19}{*}{$\begin{array}{l}\text { b) Eco-social } \\
\text { model }\end{array}$} & Intercept & -0.44 & $-0.64 \cdot-0.24$ & 1 \\
\hline & Mass & 0.05 & $0.02 \cdot 0.07$ & 1 \\
\hline & Foraging substrate (others vs arboreal) & 0.12 & $0.07 \cdot 0.17$ & 1 \\
\hline & Migratory behavior (sedentary vs migratory) & 0.05 & $0.02 \cdot 0.07$ & 1 \\
\hline & Energy content of food (PC) & 0.00 & $-0.01 \cdot 0.01$ & 0 \\
\hline & Food handling level (PC) & 0.00 & $-0.02 \cdot 0.02$ & 0 \\
\hline & Insularity (continental vs insular) & 0.00 & $-0.05 \cdot 0.06$ & 0 \\
\hline & Mean diurnal temperature range $(\mathrm{PC})$ & 0.01 & $0.00 \cdot 0.02$ & 0 \\
\hline & Annual temperature and rainfall $(\mathrm{PC})$ & -0.01 & $-0.03 \cdot 0.00$ & 0.34 \\
\hline & Climatic seasonality (PC) & 0.00 & $-0.01 \cdot 0.01$ & 0 \\
\hline & Short vs seasonal social bonds & 0.04 & $-0.02 \cdot 0.09$ & 0 \\
\hline & Short vs long-term social bonds & 0.08 & $0.02 \cdot 0.14$ & 1 \\
\hline & Colonial vs solitary breeding & 0.00 & $-0.02 \cdot 0.03$ & 0 \\
\hline & Asocial vs pair living & -0.03 & $-0.06 \cdot 0.01$ & 0 \\
\hline & Asocial vs small groups & -0.02 & $-0.06 \cdot 0.02$ & 0 \\
\hline & Asocial vs large groups & 0.00 & $-0.04 \cdot 0.03$ & 0 \\
\hline & Mass $\mathrm{x}$ foraging substrate & 0.10 & $0.06 \cdot 0.15$ & 1 \\
\hline & Mass $\mathrm{x}$ sedentariness & -0.03 & $-0.05 \cdot-0.01$ & 1 \\
\hline & Mass $x$ energy content of food (PC) & 0.02 & $0.01 \cdot 0.03$ & 1 \\
\hline \multirow{29}{*}{$\begin{array}{l}\text { c) Combined } \\
\text { model }\end{array}$} & Intercept & -0.37 & $-0.57 \cdot-0.17$ & 1 \\
\hline & Mass & -0.01 & $-0.05 \cdot 0.03$ & 0 \\
\hline & Development mode (precocial vs altricial) & 0.17 & $0.04 \cdot 0.30$ & 0.99 \\
\hline & Clutch size & -0.07 & $-0.10=-0.04$ & 1 \\
\hline & Residual egg mass & 0.10 & $0.05 \cdot 0.16$ & 1 \\
\hline & Time fed & 0.07 & $0.02 \cdot 0.12$ & 1 \\
\hline & Number of caretakers & 0.00 & $-0.01 \cdot 0.01$ & 0 \\
\hline & Mass $\mathrm{x}$ development mode & 0.18 & $0.13 \cdot 0.23$ & 1 \\
\hline & Mass $\mathrm{x}$ clutch size & 0.02 & $0.00 \cdot 0.04$ & 1 \\
\hline & Mass $\mathrm{x}$ residual egg mass & 0.07 & $0.03 \cdot 0.10$ & 1 \\
\hline & Development mode $x$ clutch size & 0.12 & $0.08 \cdot 0.16$ & 1 \\
\hline & Development mode $\mathrm{x}$ residual egg mass & 0.19 & $0.11 \cdot 0.27$ & 1 \\
\hline & Development mode $\mathrm{x}$ time fed & 0.07 & $-0.01 \cdot 0.15$ & 0.02 \\
\hline & Residual egg mass $x$ clutch size & 0.09 & $0.07 \cdot 0.11$ & 1 \\
\hline & Foraging substrate (others vs arboreal) & 0.10 & $0.05 \cdot 0.14$ & 1 \\
\hline & Migratory behavior (sedentary vs migratory) & 0.05 & $0.02 \cdot 0.07$ & 1 \\
\hline & Energy content of food (PC) & 0.01 & $0.00 \cdot 0.03$ & 0.05 \\
\hline & Food handling level (PC) & 0.02 & $-0.01 \cdot 0.05$ & 0 \\
\hline & Insularity (continental vs insular) & 0.01 & $-0.04 \cdot 0.05$ & 0 \\
\hline & Mean diurnal temperature range $(\mathrm{PC})$ & 0.00 & $-0.01 \cdot 0.01$ & 0 \\
\hline & Annual temperature and rainfall (PC) & -0.01 & $-0.02 \cdot 0.00$ & 0 \\
\hline & Climatic seasonality (PC) & 0.00 & $0.00 \cdot 0.01$ & 0 \\
\hline & Short vs seasonal social bonds & -0.01 & $-0.06 \cdot 0.04$ & 0 \\
\hline & Short vs long-term social bonds & 0.02 & $-0.03 \cdot 0.08$ & 0 \\
\hline & Colonial vs solitary breeding & -0.01 & $-0.03 \cdot 0.02$ & 0 \\
\hline & Asocial vs pair living & -0.03 & $-0.06 \cdot 0.01$ & 0.01 \\
\hline & Asocial vs small groups & -0.02 & $-0.06 \cdot 0.02$ & 0 \\
\hline & Asocial vs large groups & -0.01 & $-0.04 \cdot 0.03$ & 0 \\
\hline & Mass $\mathrm{x}$ foraging substrate & 0.06 & $0.02 \cdot 0.10$ & 1 \\
\hline
\end{tabular}


bioRxiv preprint doi: https://doi.org/10.1101/2021.12.19.470191; this version posted December 21,2021 . The copyright holder for this preprint (which was not certified by peer review) is the author/funder, who has granted bioRxiv a license to display the preprint in perpetuity. It is made available under aCC-BY-NC-ND 4.0 International license.

\begin{tabular}{|c|c|c|c|c|}
\hline & \multirow{4}{*}{$\begin{array}{l}\text { Mass } x \text { sedentariness } \\
\text { Developmental mode } x \text { food handling level } \\
\text { (PC) } \\
\text { Clutch size } x \text { energy content of food (PC) }\end{array}$} & -0.03 & \multirow{2}{*}{$\begin{array}{l}-0.05 \cdot-0.01 \\
-0.09 \cdot-0.02\end{array}$} & \multirow{2}{*}{$\begin{array}{l}1 \\
1\end{array}$} \\
\hline & & -0.05 & & \\
\hline & & -0.01 & $-0.02 \cdot 0.00$ & 0.36 \\
\hline & & -0.01 & $-0.03 \cdot 0.00$ & 0.96 \\
\hline \multirow{36}{*}{$\begin{array}{l}\text { d) Combined } \\
\text { model } \\
\text { including } \\
\text { longevity }\end{array}$} & Intercept & -0.36 & $-0.58 \cdot-0.14$ & 1 \\
\hline & Mass & 0.01 & $-0.04 \cdot 0.06$ & 0 \\
\hline & Development mode (precocial vs altricial) & 0.18 & $0.04 \cdot 0.33$ & 0.99 \\
\hline & Clutch size & -0.08 & $-0.12 \cdot-0.04$ & 1 \\
\hline & Residual egg mass & 0.12 & $0.05 \cdot 0.18$ & 1 \\
\hline & Time fed & 0.05 & $0.00 \cdot 0.11$ & 0.1 \\
\hline & Number of caretakers & 0.00 & $-0.01 \cdot 0.01$ & 0 \\
\hline & Mass $\mathrm{x}$ development mode & 0.15 & $0.09 \cdot 0.22$ & 1 \\
\hline & Mass $x$ clutch size & 0.01 & $-0.01 \cdot 0.03$ & 0 \\
\hline & Mass $\mathrm{x}$ residual egg mass & 0.04 & $0.00 \cdot 0.08$ & 0.26 \\
\hline & Development mode $\mathrm{x}$ clutch size & 0.13 & $0.09 \cdot 0.18$ & 1 \\
\hline & Development mode $\mathrm{x}$ residual egg mass & 0.17 & $0.08 \cdot 0.26$ & 1 \\
\hline & Development mode $x$ time fed & 0.13 & $0.04 \cdot 0.23$ & 1 \\
\hline & Residual egg mass $\mathrm{x}$ clutch size & 0.08 & $0.06 \cdot 0.11$ & 1 \\
\hline & Foraging substrate (others vs arboreal) & 0.09 & $0.04 \cdot 0.14$ & 1 \\
\hline & Migratory behavior (sedentary vs migratory) & 0.04 & $0.01 \cdot 0.07$ & 1 \\
\hline & Energy content of food (PC) & 0.01 & $0.00 \cdot 0.03$ & 0 \\
\hline & Food handling level (PC) & 0.01 & $-0.03 \cdot 0.04$ & 0 \\
\hline & Insularity (continental vs insular) & -0.01 & $-0.07 \cdot 0.05$ & 0 \\
\hline & Mean diurnal temperature range (PC) & -0.01 & $-0.02 \cdot 0.01$ & 0 \\
\hline & Annual temperature and rainfall (PC) & 0.00 & $-0.02 \cdot 0.01$ & 0 \\
\hline & Climatic seasonality (PC) & 0.00 & $-0.01 \cdot 0.01$ & 0 \\
\hline & Short vs seasonal social bonds & 0.00 & $-0.07 \cdot 0.06$ & 0 \\
\hline & Short vs long-term social bonds & 0.04 & $-0.03 \cdot 0.11$ & 0 \\
\hline & Colonial vs solitary breeding & -0.01 & $-0.04 \cdot 0.01$ & 0 \\
\hline & Asocial vs pair living & -0.02 & $-0.06 \cdot 0.02$ & 0 \\
\hline & Asocial vs small groups & -0.04 & $-0.08 \cdot 0.01$ & 0 \\
\hline & Asocial vs large groups & 0.00 & $-0.04 \cdot 0.04$ & 0 \\
\hline & Mass $\mathrm{x}$ foraging substrate & 0.06 & $0.01 \cdot 0.11$ & 0.98 \\
\hline & Mass $\mathrm{x}$ sedentariness & -0.03 & $-0.05 \cdot-0.01$ & 1 \\
\hline & Mass $x$ energy content of food (PC) & 0.01 & $-0.01 \cdot 0.02$ & 0 \\
\hline & Developmental mode $x$ food handling level (PC) & -0.05 & $-0.09 \cdot 0.00$ & 0.71 \\
\hline & Clutch size $x$ energy content of food (PC) & -0.01 & $-0.03 \cdot 0.00$ & 0.12 \\
\hline & Clutch size $x$ food handling level (PC) & -0.01 & $-0.03 \cdot 0.00$ & 0.02 \\
\hline & Longevity & 0.01 & $-0.01 \cdot 0.02$ & 0 \\
\hline & Mass $\mathrm{x}$ longevity & -0.01 & $-0.03 \cdot 0.00$ & 0.98 \\
\hline
\end{tabular}

681 Significant predictors that are supported by at least $95 \%$ of different models are highlighted in bold. Post. mean $=$ mean of the posterior distribution of a parameter, $\mathrm{Cl}=$ posterior credibility interval, $\mathrm{p}$ MCMC = averaged P-values over all 200 models with different phylogenetic trees. The Principal 684 Component analyses (PCAs) of climatic and food parameters are shown in S4 Table. 
bioRxiv preprint doi: https://doi.org/10.1101/2021.12.19.470191; this version posted December 21, 2021. The copyright holder for this

preprint (which was not certified by peer review) is the author/funder, who has granted bioRxiv a license to display the preprint in perpetuity. It is made available under aCC-BY-NC-ND 4.0 International license.

S3 Table. Additional phylogenetically controlled mixed models in MCMCgImm(33) assessing the effect of parental provisioning and eco-social parameters on the evolution of relative brain size in

\begin{tabular}{|c|c|c|c|c|c|}
\hline & Predictor & Post. mean & lower $\cdot$ upper $95 \% \mathrm{Cl}$ & $\mathrm{N}$ & pMCMC \\
\hline \multirow{31}{*}{$\begin{array}{l}\text { a) excluding } \\
\text { duration } \\
\text { parental } \\
\text { provisioning }\end{array}$} & Intercept & -0.44 & $-0.64 \cdot-0.26$ & 1000 & $<0.001$ \\
\hline & Mass & -0.01 & $-0.04 \cdot 0.03$ & 1000 & 0.77 \\
\hline & Development mode (precocial vs altricial) & 0.24 & $0.13 \cdot 0.36$ & 977 & $<0.001$ \\
\hline & Clutch size & -0.07 & $-0.10 \cdot-0.04$ & 1722 & $<0.001$ \\
\hline & Residual egg mass & 0.05 & $0.00 \cdot 0.10$ & 895 & 0.034 \\
\hline & Number of caretakers & 0.00 & $-0.01 \cdot 0.01$ & 1000 & 0.42 \\
\hline & Mass $\mathrm{x}$ development mode & 0.19 & $0.14 \cdot 0.24$ & 1000 & $<0.001$ \\
\hline & Mass $\mathrm{x}$ clutch size & 0.02 & $0.01 \cdot 0.03$ & 1000 & $<0.001$ \\
\hline & Mass $\mathrm{x}$ residual egg mass & 0.11 & $0.08 \cdot 0.14$ & 1117 & $<0.001$ \\
\hline & Development mode $x$ clutch size & 0.11 & $0.07 \cdot 0.15$ & 1446 & $<0.001$ \\
\hline & Development mode $\mathrm{x}$ residual egg mass & 0.27 & $0.21 \cdot 0.34$ & 1000 & $<0.001$ \\
\hline & Residual egg mass $\mathrm{x}$ clutch size & 0.08 & $0.06 \cdot 0.10$ & 1000 & $<0.001$ \\
\hline & Foraging substrate (others vs arboreal) & 0.11 & $0.08 \cdot 0.15$ & 1000 & $<0.001$ \\
\hline & Migratory behavior (sedentary vs migratory) & 0.05 & $0.03 \cdot 0.07$ & 980 & $<0.001$ \\
\hline & Energy content of food (PC) & 0.02 & $0.00 \cdot 0.03$ & 1000 & 0.008 \\
\hline & Food handling level (PC) & 0.02 & $-0.01 \cdot 0.04$ & 1151 & 0.16 \\
\hline & Insularity (continental vs insular) & 0.03 & $-0.01 \cdot 0.08$ & 1000 & 0.13 \\
\hline & Mean diurnal temperature range (PC) & 0.00 & $-0.01 \cdot 0.01$ & 1220 & 1.00 \\
\hline & Annual temperature and rainfall $(\mathrm{PC})$ & -0.01 & $-0.02 \cdot 0.00$ & 1000 & 0.018 \\
\hline & Climatic seasonality (PC) & 0.00 & $-0.01 \cdot 0.01$ & 1000 & 0.90 \\
\hline & Short vs seasonal social bonds & -0.02 & $-0.07 \cdot 0.03$ & 844 & 0.48 \\
\hline & Short vs long-term social bonds & 0.01 & $-0.04 \cdot 0.06$ & 876 & 0.77 \\
\hline & Colonial vs solitary breeding & 0.00 & $-0.02 \cdot 0.02$ & 1000 & 0.73 \\
\hline & Asocial vs pair living & -0.01 & $-0.05 \cdot 0.01$ & 978 & 0.36 \\
\hline & Asocial vs small groups & -0.01 & $-0.05 \cdot 0.02$ & 1000 & 0.61 \\
\hline & Asocial vs large groups & 0.01 & $-0.02 \cdot 0.04$ & 1000 & 0.38 \\
\hline & Mass $\mathrm{x}$ foraging substrate & 0.07 & $0.03 \cdot 0.11$ & 1000 & 0.002 \\
\hline & Mass $\mathrm{x}$ sedentariness & -0.03 & $-0.05 \cdot-0.01$ & 1000 & $<0.001$ \\
\hline & Developmental mode $\mathrm{x}$ food handling level $(\mathrm{PC})$ & -0.04 & $-0.08 \cdot-0.01$ & 1115 & 0.016 \\
\hline & Clutch size $x$ energy content of food (PC) & -0.01 & $-0.02 \cdot 0.00$ & 1000 & 0.044 \\
\hline & Clutch size $x$ food handling level (PC) & -0.01 & $-0.02 \cdot 0.00$ & 1189 & 0.02 \\
\hline \multirow{27}{*}{$\begin{array}{l}\text { b) excluding } \\
\text { parental } \\
\text { provisioning } \\
\text { and social } \\
\text { grouping }\end{array}$} & Intercept & -0.45 & $-0.62 \cdot-0.27$ & 1000 & $<0.001$ \\
\hline & Mass & 0.00 & $-0.04 \cdot 0.04$ & 1099 & 0.99 \\
\hline & Development mode (precocial vs altricial) & 0.23 & $0.12 \cdot 0.34$ & 1000 & $<0.001$ \\
\hline & Clutch size & -0.06 & $-0.09 \cdot-0.04$ & 1000 & $<0.001$ \\
\hline & Residual egg mass & 0.08 & $0.03 \cdot 0.13$ & 1000 & 0.006 \\
\hline & Number of caretakers & 0.01 & $0.00 \cdot 0.01$ & 1020 & 0.18 \\
\hline & Mass $\mathrm{x}$ development mode & 0.16 & $0.11 \cdot 0.21$ & 1000 & $<0.001$ \\
\hline & Mass $\mathrm{x}$ clutch size & 0.02 & $0.00 \cdot 0.03$ & 1108 & 0.008 \\
\hline & Mass $\mathrm{x}$ residual egg mass & 0.09 & $0.06 \cdot 0.12$ & 1097 & $<0.001$ \\
\hline & Development mode $\mathrm{x}$ clutch size & 0.09 & $0.05 \cdot 0.12$ & 1000 & $<0.001$ \\
\hline & Development mode $\mathrm{x}$ residual egg mass & 0.19 & $0.14 \cdot 0.26$ & 1000 & $<0.001$ \\
\hline & Residual egg mass $x$ clutch size & 0.08 & $0.06 \cdot 0.10$ & 1000 & $<0.001$ \\
\hline & Foraging substrate (others vs arboreal) & 0.11 & $0.08 \cdot 0.15$ & 1000 & $<0.001$ \\
\hline & Migratory behavior (sedentary vs migratory) & 0.06 & $0.04 \cdot 0.07$ & 1000 & $<0.001$ \\
\hline & Energy content of food $(\mathrm{PC})$ & 0.01 & $0.00 \cdot 0.02$ & 1093 & 0.062 \\
\hline & Food handling level (PC) & 0.01 & $-0.01 \cdot 0.04$ & 1000 & 0.34 \\
\hline & Insularity (continental vs insular) & 0.02 & $-0.03 \cdot 0.06$ & 1000 & 0.41 \\
\hline & Mean diurnal temperature range $(\mathrm{PC})$ & 0.00 & $-0.01 \cdot 0.01$ & 1000 & 0.60 \\
\hline & Annual temperature and rainfall (PC) & -0.01 & $-0.02 \cdot 0.00$ & 1359 & 0.046 \\
\hline & Climatic seasonality $(\mathrm{PC})$ & 0.00 & $-0.01 \cdot 0.01$ & 1506 & 0.79 \\
\hline & Short vs seasonal social bonds & -0.02 & $-0.07 \cdot 0.03$ & 1100 & 0.48 \\
\hline & Short vs long-term social bonds & 0.01 & $-0.04 \cdot 0.06$ & 1000 & 0.79 \\
\hline & Colonial vs solitary breeding & -0.01 & $-0.03 \cdot 0.02$ & 1000 & 0.61 \\
\hline & Mass $\mathrm{x}$ foraging substrate & 0.07 & $0.04 \cdot 0.11$ & 1000 & $<0.001$ \\
\hline & Mass $\mathrm{x}$ sedentariness & -0.03 & $-0.05 \cdot-0.01$ & 1000 & 0.002 \\
\hline & Developmental mode $x$ food handling level $(P C)$ & -0.03 & $-0.06 \cdot 0.00$ & 1000 & 0.052 \\
\hline & Clutch size $x$ food handling level (PC) & -0.01 & $-0.02 \cdot 0.00$ & 1000 & 0.008 \\
\hline \multirow{6}{*}{$\begin{array}{l}\text { c) using } 4 \\
\text { developmental } \\
\text { mode } \\
\text { categories }\end{array}$} & Intercept & -0.11 & $-0.32 \cdot 0.06$ & 1000 & 0.25 \\
\hline & Mass & 0.17 & $0.14 \cdot 0.21$ & 1134 & $<0.001$ \\
\hline & Development mode (altricial vs precocial) & -0.23 & $-0.53 \cdot 0.11$ & 1000 & 0.16 \\
\hline & Development mode (altricial vs semi-altricial) & -0.13 & $-0.32 \cdot 0.05$ & 985 & 0.17 \\
\hline & Development mode (altricial vs semi-precocial) & -0.26 & $-0.41 \cdot-0.11$ & 1000 & $<0.001$ \\
\hline & Clutch size & 0.02 & $-0.01 \cdot 0.05$ & 1000 & 0.11 \\
\hline
\end{tabular}


bioRxiv preprint doi: https://doi.org/10.1101/2021.12.19.470191; this version posted December 21, 2021. The copyright holder for this preprint (which was not certified by peer review) is the author/funder, who has granted bioRxiv a license to display the preprint in perpetuity. It is made available under aCC-BY-NC-ND 4.0 International license.

\begin{tabular}{|c|c|c|c|c|}
\hline Residual egg mass & 0.29 & $0.22 \cdot 0.36$ & 1000 & $<0.001$ \\
\hline Time fed & 0.20 & $0.13 \cdot 0.27$ & 874 & $<0.001$ \\
\hline Number of caretakers & 0.00 & $-0.01 \cdot 0.01$ & 1000 & 0.71 \\
\hline Mass $\mathrm{x}$ development mode (altricial vs precocial) & -0.22 & $-0.28 \cdot-0.16$ & 1120 & $<0.001$ \\
\hline Mass $\mathrm{x}$ development mode (altricial vs semi-altricial) & -0.03 & $-0.12 \cdot 0.07$ & 1000 & 0.54 \\
\hline Mass $\mathrm{x}$ development mode (alt. vs semi-precocial) & -0.13 & $-0.21 \cdot-0.06$ & 1000 & $<0.001$ \\
\hline Mass $x$ clutch size & 0.02 & $0.00 \cdot 0.04$ & 1000 & 0.05 \\
\hline Mass $\mathrm{x}$ residual egg mass & 0.06 & $0.02 \cdot 0.10$ & 1000 & 0.002 \\
\hline Development mode (alt. vs precocial) $x$ clutch size & -0.06 & $-0.11 \cdot-0.01$ & 1000 & 0.012 \\
\hline Development mode (alt. vs semi-altricial) $x$ clutch size & -0.01 & $-0.07 \cdot 0.07$ & 1000 & 0.89 \\
\hline Development mode (alt. vs semi-prec.) $x$ clutch size & -0.13 & $-0.19 \cdot-0.07$ & 1000 & $<0.001$ \\
\hline Develop. mode (alt. vs prec.) $\mathrm{x}$ residual egg mass & -0.19 & $-0.33 \cdot-0.08$ & 1095 & 0.002 \\
\hline Develop. mode (alt. vs semi-alt.) $x$ residual egg mass & 0.06 & $-0.14 \cdot 0.25$ & 1000 & 0.484 \\
\hline Develop. mode (alt. vs semi-prec.) $x$ res. egg mass & -0.19 & $-0.29 \cdot-0.08$ & 1095 & $<0.001$ \\
\hline Development mode (altricial vs precocial) $x$ time fed & -0.12 & $-0.30 \cdot 0.06$ & 1000 & 0.164 \\
\hline Development mode (alt. vs semi-altricial) $x$ time fed & -0.14 & $-0.3 \cdot-0.01$ & 764 & 0.048 \\
\hline Development mode (alt. vs semi-prec.) $x$ time fed & -0.18 & $-0.27 \cdot-0.07$ & 1000 & $<0.001$ \\
\hline Residual egg mass $x$ clutch size & 0.09 & $0.05 \cdot 0.12$ & 1000 & $<0.001$ \\
\hline
\end{tabular}

690 Model a) combined model excluding the duration of parental provisioning: $N=1,458$ species; model b) combined model excluding parental provisioning and social grouping parameters: $\mathrm{N}=1,594$ species; model c) using four developmental mode categories: N=1,176 species. Significant predictors

693 are highlighted in bold. Post. mean = mean of the posterior distribution of a parameter, $\mathrm{Cl}=$ posterior credibility interval, $\mathrm{N}=$ effective sample size (corrected for MCMC timeseries autocorrelation). The Principal Component analyses (PCAs) of climatic and food parameters are 696 shown in S4 Table. 
S4 Table. Principal Component Analyses (PCA) loadings and variance explained. Loadings of the main contributors to the different component are highlighted in bold.

\begin{tabular}{|c|c|c|c|}
\hline a) Food PCA & PC F1 & PC F2 & \\
\hline Food energy content / 100g & 0.12 & 0.99 & \\
\hline Food fiber content / 100g & -0.96 & -0.04 & \\
\hline Food handling levels & 0.95 & 0.17 & \\
\hline SS loadings & 1.84 & 1.01 & \\
\hline Proportion Variance & 0.61 & 0.34 & \\
\hline Cumulative Variance & 0.61 & 0.95 & \\
\hline Proportion Explained & 0.64 & 0.36 & \\
\hline Cumulative Proportion & 0.64 & 1.00 & \\
\hline b) Climatic PCA & PC C1 & PC C2 & PC C3 \\
\hline Bio1_mean Annual Mean Temperature & 0.89 & 0.06 & 0.04 \\
\hline Bio1_stdev & -0.62 & 0.53 & 0.04 \\
\hline Bio2_mean Mean Diurnal Range & -0.14 & 0.19 & 0.81 \\
\hline Bio2_stdev & -0.30 & 0.71 & 0.43 \\
\hline Bio3_mean Isothermality & 0.89 & -0.02 & -0.22 \\
\hline Bio3_stdev & -0.02 & 0.87 & 0.10 \\
\hline Bio4_mean Temperature Seasonality & -0.96 & 0.02 & 0.13 \\
\hline Bio4_stdev & -0.78 & 0.50 & 0.14 \\
\hline Bio7_mean Temperature Annual Range & -0.90 & 0.08 & 0.34 \\
\hline Bio7_stdev & -0.69 & 0.61 & 0.22 \\
\hline Bio12_mean Annual Precipitation & 0.56 & -0.01 & -0.73 \\
\hline Bio12_stdev & 0.28 & 0.65 & -0.44 \\
\hline Bio15_mean Precipitation Seasonality & 0.01 & 0.17 & 0.80 \\
\hline Bio15_stdev & -0.11 & 0.74 & 0.39 \\
\hline SS loadings & 5.32 & 3.22 & 2.63 \\
\hline Proportion Variance & 0.38 & 0.23 & 0.19 \\
\hline Cumulative Variance & 0.38 & 0.61 & 0.80 \\
\hline Proportion Explained & 0.48 & 0.29 & 0.24 \\
\hline Cumulative Proportion & 0.48 & 0.76 & 1.00 \\
\hline
\end{tabular}

a) Food items PCA. b) Climatic PCA. 
705 S5 Table. Variance inflation factor (VIF) analyses of all parameters included in the combined model.

\begin{tabular}{lc}
\hline Predictor & VIF \\
\hline Mass & 1.188 \\
Development mode (precocial vs altricial) & 1.162 \\
Clutch size & 1.219 \\
Residual egg mass & 1.273 \\
Time fed & 1.906 \\
Number of caretakers & 1.167 \\
Foraging substrate (others vs arboreal) & 1.075 \\
Migratory behavior (sedentary vs migratory) & 1.352 \\
Energy content of food (PC) & 1.095 \\
Food handling level (PC) & 1.135 \\
Insularity (continental vs insular) & 1.564 \\
Mean diurnal temperature range (PC) & 1.600 \\
Annual temperature and rainfall (PC) & 2.076 \\
Climatic seasonality (PC) & 1.108 \\
Social bonds & 1.567 \\
Colonial vs solitary breeding & 1.031 \\
Grouping pattern & 1.073 \\
\hline
\end{tabular}

Variance inflation factors (VIF) were calculated from a Bayesian phylogenetically controlled mixed model including parental provisioning and eco-social predictors. VIF is assumed to be the term

711 inflating the regression coefficient's variance estimate $\widehat{\operatorname{var}}\left(\beta_{i}\right)=\left(\frac{s^{2}}{(n-1) \widehat{v a r}\left(X_{i}\right)}\right) \frac{1}{1-R_{i}^{2}}=$ $\left(\frac{s^{2}}{(n-1) \hat{v a r}\left(X_{i}\right)}\right) V I F_{i}$, where $\mathrm{s}^{2}$ is the root mean squared error of regression, $\mathrm{n}$ is the sample size, $\mathrm{X}_{\mathrm{i}}$ is the $\mathrm{i}$-th column of the design matrix. $\mathrm{R}_{\mathrm{i}}{ }^{2}$ then becomes the GLMM $\mathrm{R}^{2}$ analogue for the model: $X_{i}=$ $714 \quad \alpha_{0}+\alpha_{1} X_{1}+\cdots+\alpha_{i-1} X_{i-1}+\alpha_{i+1} X_{i+1}+\cdots+\alpha_{k} X_{k}$ 
bioRxiv preprint doi: https://doi.org/10.1101/2021.12.19.470191; this version posted December 21,2021 . The copyright holder for this

preprint (which was not certified by peer review) is the author/funder, who has granted bioRxiv a license to display the preprint in perpetuity. It is made available under aCC-BY-NC-ND 4.0 International license.

S6 Table. Model comparisons of the models included in the phylogenetic d-separation path

analyses.

\begin{tabular}{|c|c|c|c|c|c|c|c|c|c|}
\hline & Model & $\mathrm{C}$ & $\mathrm{ClCc}$ & $\Delta \mathrm{ClCc}$ & & Model & $\mathrm{C}$ & $\mathrm{CICc}$ & $\Delta \mathrm{ClCc}$ \\
\hline a, Parental & Model_A1 & 54.22 & 92.88 & 0.00 & b, Eco-social & Model_E1 & 222.73 & 282.24 & 0.00 \\
\hline provisioning & Model_A2 & 62.77 & 99.36 & 6.48 & model & Model_E2 & 238.15 & 291.37 & 9.13 \\
\hline \multirow[t]{44}{*}{ model } & Model_A3 & 62.07 & 100.72 & 7.85 & & Model_E3 & 241.22 & 296.54 & 14.29 \\
\hline & Model_A4 & 72.04 & 110.70 & 17.82 & & Model_E4 & 242.74 & 298.06 & 15.82 \\
\hline & Model_A5 & 79.89 & 118.54 & 25.67 & & Model_E5 & 242.16 & 299.57 & 17.33 \\
\hline & Model_A6 & 87.46 & 124.05 & 31.17 & & Model_E6 & 249.66 & 302.88 & 20.63 \\
\hline & Model_A7 & 91.65 & 128.24 & 35.36 & & Model_E7 & 254.88 & 303.92 & 21.67 \\
\hline & Model_A8 & 99.22 & 133.75 & 40.87 & & Model_E8 & 249.07 & 304.39 & 22.14 \\
\hline & Model_A9 & 116.06 & 150.59 & 57.71 & & Model_E9 & 258.17 & 307.21 & 24.96 \\
\hline & Model_A10 & 119.17 & 151.64 & 58.77 & & Model_E10 & 257.58 & 308.71 & 26.46 \\
\hline & Model_A11 & 115.36 & 151.95 & 59.07 & & Model_E11 & 255.57 & 308.79 & 26.54 \\
\hline & Model_A12 & 118.47 & 153.00 & 60.12 & & Model_E12 & 260.31 & 309.35 & 27.10 \\
\hline & Model_A13 & 134.86 & 169.39 & 76.51 & & Model_E13 & 265.08 & 312.04 & 29.79 \\
\hline & Model_A14 & 133.18 & 169.77 & 76.89 & & Model_E14 & 261.24 & 312.37 & 30.12 \\
\hline & Model_A15 & 134.15 & 170.74 & 77.87 & & Model_E15 & 264.49 & 313.54 & 31.29 \\
\hline & Model_A16 & 136.29 & 170.82 & 77.94 & & Model_E16 & 260.65 & 313.87 & 31.62 \\
\hline & Model_A17 & 141.97 & 174.44 & 81.56 & & Model_E17 & 268.15 & 317.19 & 34.95 \\
\hline & Model_A18 & 141.26 & 175.79 & 82.92 & & Model_E18 & 267.56 & 318.69 & 36.45 \\
\hline & Model_A19 & 141.72 & 176.25 & 83.37 & & Model_E19 & 274.89 & 319.77 & 37.53 \\
\hline & Model_A20 & 144.94 & 179.47 & 86.59 & & Model_E20 & 274.31 & 321.26 & 39.02 \\
\hline & Model_A21 & 148.05 & 180.52 & 87.64 & & Model_E21 & 272.62 & 323.75 & 41.50 \\
\hline & Model_A22 & 152.56 & 185.03 & 92.15 & & Model_E22 & 281.81 & 324.61 & 42.36 \\
\hline & Model_A23 & 151.97 & 188.57 & 95.69 & & Model_E23 & 275.81 & 324.85 & 42.60 \\
\hline & Model_A24 & 154.53 & 189.06 & 96.18 & & Model_E24 & 280.54 & 325.42 & 43.18 \\
\hline & Model_A25 & 160.02 & 192.49 & 99.62 & & Model_E25 & 281.22 & 326.10 & 43.85 \\
\hline & Model_A26 & 159.09 & 193.61 & 100.74 & & Model_E26 & 275.00 & 326.13 & 43.88 \\
\hline & Model_A27 & 159.54 & 194.07 & 101.20 & & Model_E27 & 279.73 & 326.69 & 44.45 \\
\hline & Model_A28 & 160.00 & 194.53 & 101.65 & & Model_E28 & 282.72 & 329.68 & 47.43 \\
\hline & Model_A29 & 163.73 & 198.26 & 105.39 & & Model_E29 & 287.46 & 330.26 & 48.01 \\
\hline & Model_A30 & 170.85 & 203.32 & 110.44 & & Model_E30 & 281.91 & 330.95 & 48.71 \\
\hline & Model_A31 & 171.30 & 203.77 & 110.90 & & Model_E31 & 286.65 & 331.53 & 49.28 \\
\hline & Model_A32 & 172.36 & 206.88 & 114.01 & & Model_E32 & 292.64 & 339.59 & 57.35 \\
\hline & Model_A33 & 177.82 & 212.35 & 119.48 & & Model_E33 & 292.05 & 341.09 & 58.84 \\
\hline & Model_A34 & 181.43 & 213.90 & 121.03 & & Model_E34 & 299.55 & 344.43 & 62.18 \\
\hline & Model_A35 & 187.43 & 217.84 & 124.96 & & Model_E35 & 298.96 & 345.92 & 63.67 \\
\hline & Model_A36 & 187.41 & 219.87 & 127.00 & & Model_E36 & 308.51 & 351.31 & 69.06 \\
\hline & Model_A37 & 187.41 & 219.87 & 127.00 & & Model_E37 & 316.24 & 354.90 & 72.65 \\
\hline & Model_A38 & 188.15 & 220.62 & 127.74 & c, Combined & Model_C1 & 422.63 & 544.76 & 0.00 \\
\hline & Model_A39 & 188.90 & 221.37 & 128.49 & model & Model_C2 & 420.92 & 545.26 & 0.50 \\
\hline & Model_A40 & 191.26 & 221.67 & 128.80 & & Model_C3 & 430.92 & 548.62 & 3.87 \\
\hline & Model_A41 & 187.44 & 221.97 & 129.09 & & Model_C4 & 429.21 & 549.12 & 4.36 \\
\hline & Model_A42 & 190.56 & 223.02 & 130.15 & & Model_C5 & 429.68 & 549.59 & 4.83 \\
\hline & Model_A43 & 205.23 & 237.70 & 144.82 & & Model_C6 & 433.82 & 551.52 & 6.76 \\
\hline & Model_A44 & 205.23 & 237.70 & 144.82 & & Model_C7 & 433.20 & 553.11 & 8.35 \\
\hline & Model_A45 & 205.26 & 239.79 & 146.92 & & Model_C8 & 444.99 & 560.49 & 15.73 \\
\hline & Model_A46 & 208.38 & 240.85 & 147.97 & & Model_C9 & 471.68 & 574.03 & 29.27 \\
\hline & & & & & & Model_C10 & 470.11 & 576.82 & 32.06 \\
\hline & & & & & & Model_C11 & 933.65 & 991.06 & 446.31 \\
\hline
\end{tabular}


bioRxiv preprint doi: https://doi.org/10.1101/2021.12.19.470191; this version posted December $21,2021$. The copyright holder for this preprint (which was not certified by peer review) is the author/funder, who has granted bioRxiv a license to display the preprint in perpetuity. It is made available under aCC-BY-NC-ND 4.0 International license.

720 Models are sorted by their $\mathrm{CIC} c$ values. Parental provisioning models with a $\Delta \mathrm{CICC}>150$ are not shown ( $\mathrm{N}=21$ models). C: Fisher's C-statistics. The topologies of the top models ( $\mathrm{N}=15$ for parental provisioning and eco-social model, $\mathrm{N}=10$ for combined model) are illustrated in $\mathrm{S} 2-4$ Figs. 